\title{
5 Degree and direction of environmental policy convergence: analysis of aggregate data
}

\author{
CHRISTOPH KNILL, THOMAS SOMMERER AND \\ KATHARINA HOLZINGER
}

\section{I INTRODUCTION}

This chapter provides an overview of the empirically found patterns of cross-national policy convergence. The central questions addressed are the following. First, are the environmental policies of the countries under study actually converging and, if so, to what extent? Second, what is the direction of policy convergence; i.e., does convergence coincide with an upward or downward shift of regulatory levels? Third, to what extent do our empirical findings vary across different policy dimensions (presence-of-policies, policy instruments and policy settings) and policy types (trade-related versus non-traderelated policies, obligatory versus non-obligatory policies|?

To answer these questions, we rely on aggregate data analysis to measure the degree and direction of convergence. This way, it is possible to highlight general convergence patterns for the countries and policies under study. In addition to the presentation of aggregate data, we illustrate different convergence patterns for individual policy items. The items reflect the different dimensions (policy presence, instruments and settings) and policy types under study.

For measuring the degree of convergence (i.e., the extent of changes in policy similarity over time), we use several concepts that are commonly applied in the literature (cf. Heichel, Pape and Sommerer 2005 and chapter 3 above). First, to analyse convergence with regard to the presence of policies and policy instruments, 
we rely on the concept of adoption rates. This approach, which is typically used in research on policy diffusion, gives us information on the spread of policies and instruments across countries. The more countries adopt a certain policy or instrument, the more the variation of their policy and instrument repertoires will decrease. Hence, from this perspective, an increase in adoption rates implies growing policy similarity across countries.

This approach is closely related to the second concept of sigmaconvergence which we apply to analyse cross-national convergence with regard to the dimension of policy settings. According to this approach, convergence reflects the result of a decrease in the variation coefficient. By calculating changes in the regulatory mean, this way of measurement at the same time allows us to answer the second question raised above, namely, the extent to which we can observe a change in regulatory levels over time.

In addition and complementarily to sigma-convergence, two further convergence concepts have been applied in the literature. The concept of beta-convergence complements the assessments of changes in variation coefficients by analysing the extent to which laggard countries over time have caught up with the leader countries. While beta-convergence only allows for the identification of processes of catching up or further drifting apart between countries, the concept of gamma-convergence, which is based on the analysis of changes in country rankings with respect to the regulatory strictness of their policies, provides an instrument for measuring the extent to which catching up actually was accompanied by processes of overtaking. Gamma-convergence is measured by the degree of rank correlation; convergence presumes that the ranking in $t_{0}$ does not correlate to the ranking in $\mathbf{t}_{1}$.

The remainder of this chapter is structured as follows. In section 5.2, we analyse convergence patterns regarding the presence of policies, taking adoption rates as analytical starting point. In section 5.3 , the focus is on convergence of policy instruments, while section 5.4 is dedicated to the investigation of mean changes 
and convergence of policy settings. The concluding section (5.5) summarises the results and discusses the limits of aggregate approaches to analyse policy convergence.

\subsection{CONVERGENCE IN TERMS OF POLICY PRESENCE:} ADOPTION RATES

The least demanding indicator for policy convergence is to focus on the extent to which countries have developed a policy at all in response to a certain environmental problem. According to this criterion, policy convergence increases with the extent to which countries have a certain policy in place, regardless of the instrument types and setting levels that are applied to achieve the policy objectives.

In the literature on policy diffusion, adoption rates are the most common approach to investigating convergence with regard to the presence of policies. Adoption rates not only include information on the number of countries that have introduced a certain policy, but also on the extent to which the number of adopters changes over time. In the following, we first give a comprehensive overview over adoption rates for the whole policy sample under investigation. In a second step, we illustrate typical adoption patterns that can be observed empirically.

\subsubsection{General patterns}

Starting with the development for the whole sample of the forty policies under investigation, we find a continuous spread of environmental policies across countries (see table 5.1). So, the average adoption rate continuously grew over time, with almost a doubling of the rate during each decade under investigation. From a modest average adoption rate of 11 per cent in 1970, all of the forty environmental policies under study had already been adopted in 46 per cent of all countries in the sample by 1990 . By 2000 , the average adoption rate had further increased to 78 per cent, including several policies with an adoption rate of 100 per cent. By contrast, there are only few policies in our sample that were spreading comparatively slowly so far, implying rather low adoption rates. 


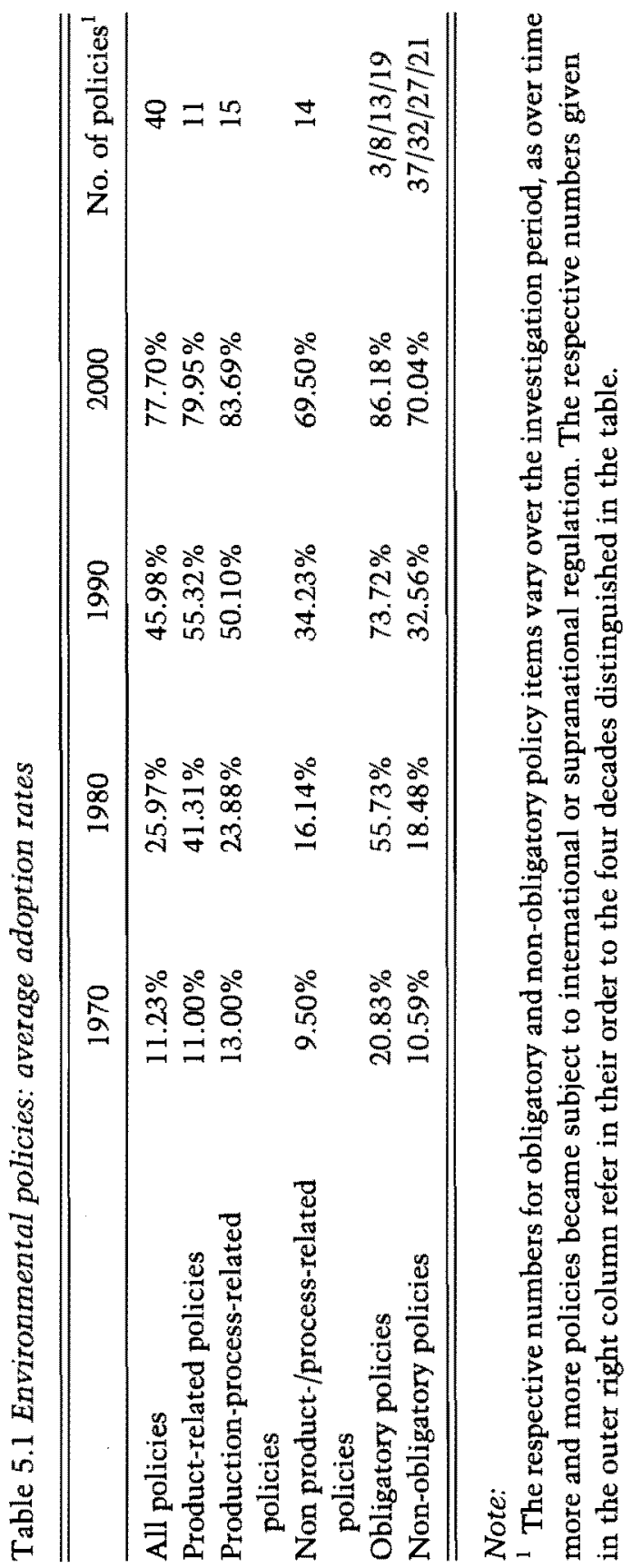


A closer look at the different policy sub-groups reveals, however, that average adoption rates vary across policy types. First, until 1990 adoption rates for obligatory policies [which are subject to international harmonisation! are more than two times higher than for non-obligatory policies. However, convergence degrees for nonobligatory policies were considerably catching up during the 1990s: whereas obligatory policies are on average adopted by 86 per cent of the twenty-four countries under study, the respective rate for non-obligatory policies is already around 70 per cent. Second, with the exception of the values for 1980, the spreading patterns for trade-related policies are rather similar, regardless whether product or process-related measures are concerned. Third, and similar to the difference between obligatory and non-obligatory policies, we can observe a considerable, albeit less pronounced, gap in adoption rates between trade-related and non-trade-related policies, including a similar process of catching-up of the latter from the 1990s onwards.

Table 5.2 presents a more detailed overview, covering adoption rates for all forty policies under investigation. According to their adoption rate level in the year 2000 , the policies are divided into four sub-groups, including policies which have been adopted in 25 , 50,75 and 90 per cent of all countries under study by the year 2000 . Moreover, the table gives information on the policy type. While the extent to which policies are trade-related or not does not change, the nature of the policies as non-obligatory or obligatory might vary over time, as a result of growing harmonisation activities at the supranational or international level. This development is indicated by bold type in the table.

The table indicates several patterns with regard to the crossnational spread of environmental policies. First, the data show that the extent to which policies are trade-related and obligatory has a positive influence on the level of the adoption rates. For the two groups with relatively high adoption rates in the year 2000 lover 75 per cent and over 90 per cent), the numbers of policies that are 
Table 5.2 Environmental policies: adoption rates over time

\begin{tabular}{|c|c|c|c|c|c|}
\hline & $\begin{array}{l}\text { Trade- } \\
\text { related }\end{array}$ & 1970 & 1980 & 1990 & 2000 \\
\hline Forest protection & NPP & $79.0 \%$ & $95.8 \%$ & $100.0 \%$ & $100.0 \%$ \\
\hline Lead in petrol & $\mathbf{P}$ & $29.2 \%$ & $70.8 \%$ & $91.7 \%$ & $100.0 \%$ \\
\hline $\begin{array}{l}\text { Passenger cars CO } \\
\text { emissions }\end{array}$ & $\mathbf{P}$ & $16.7 \%$ & $66.7 \%$ & $83.3 \%$ & $100.0 \%$ \\
\hline $\begin{array}{l}\text { Passenger cars HC } \\
\text { emissions }\end{array}$ & $\mathbf{P}$ & $8.3 \%$ & $62.5 \%$ & $79.2 \%$ & $95.8 \%$ \\
\hline $\begin{array}{l}\text { Industrial discharges } \\
\text { in surface water } \\
\text { copper }\end{array}$ & PP & $25.0 \%$ & $41.7 \%$ & $70.8 \%$ & $95.8 \%$ \\
\hline $\begin{array}{l}\text { Industrial discharges } \\
\text { in surface water } \\
\text { lead }\end{array}$ & pp & $25.0 \%$ & $41.7 \%$ & $70.8 \%$ & $95.8 \%$ \\
\hline $\begin{array}{l}\text { Industrial discharges } \\
\text { in surface water } \\
\text { chromium }\end{array}$ & PP & $25.0 \%$ & $41.7 \%$ & $70.8 \%$ & $95.8 \%$ \\
\hline $\begin{array}{l}\text { Industrial discharges } \\
\text { in surface water } \\
\text { zinc }\end{array}$ & PP & $25.0 \%$ & $41.7 \%$ & $70.8 \%$ & $95.8 \%$ \\
\hline $\begin{array}{l}\text { Large combustion } \\
\text { plants } \mathrm{SO}_{2} \\
\text { emissions }\end{array}$ & PP & $16.7 \%$ & $29.2 \%$ & $66.7 \%$ & $95.8 \%$ \\
\hline $\begin{array}{l}\text { Large combustion } \\
\text { plants dust } \\
\text { emissions }\end{array}$ & PP & $8.3 \%$ & $29.2 \%$ & $62.5 \%$ & $95.8 \%$ \\
\hline $\begin{array}{l}\text { Environmental } \\
\text { impact assessment }\end{array}$ & NPP & $4.2 \%$ & $8.3 \%$ & $62.5 \%$ & $95.8 \%$ \\
\hline $\begin{array}{l}\text { Large combustion } \\
\text { plants NOx } \\
\text { emissions }\end{array}$ & pp & $8.3 \%$ & $16.7 \%$ & $58.3 \%$ & $95.8 \%$ \\
\hline $\begin{array}{l}\text { Coliforms in bathing } \\
\text { water }\end{array}$ & NPP & $20.8 \%$ & $45.8 \%$ & $83.3 \%$ & $91.7 \%$ \\
\hline $\begin{array}{l}\text { Passenger cars NOx } \\
\text { emissions }\end{array}$ & $\mathbf{P}$ & - & $54.2 \%$ & $75.0 \%$ & $91.7 \%$ \\
\hline $\begin{array}{l}\text { Electricity from } \\
\text { renewable sources }\end{array}$ & PP & $4.2 \%$ & $8.3 \%$ & $41.7 \%$ & $91.7 \%$ \\
\hline
\end{tabular}


Table 5.2 (cont.)

\begin{tabular}{|c|c|c|c|c|c|}
\hline & $\begin{array}{l}\text { Trade- } \\
\text { related }\end{array}$ & 1970 & 1980 & 1990 & 2000 \\
\hline $\begin{array}{l}\text { Hazardous } \\
\text { substances in } \\
\text { detergents }\end{array}$ & $\mathrm{P}$ & $8.3 \%$ & $54.2 \%$ & $75.0 \%$ & $87.5 \%$ \\
\hline $\begin{array}{l}\text { Noise level working } \\
\text { environment }\end{array}$ & PP & $8.3 \%$ & $25.0 \%$ & $70.8 \%$ & $87.5 \%$ \\
\hline $\begin{array}{l}\text { Industrial discharges } \\
\text { in surface water } \\
\text { BOD }\end{array}$ & PP & $25.0 \%$ & $37.5 \%$ & $58.3 \%$ & $87.5 \%$ \\
\hline $\begin{array}{l}\text { Sustainability: } \\
\text { reference in } \\
\text { legislation }\end{array}$ & NPP & - & - & $25.0 \%$ & $87.5 \%$ \\
\hline $\begin{array}{l}\text { Energy efficiency of } \\
\text { refrigerators }\end{array}$ & $\mathbf{P}$ & - & $4.2 \%$ & - & $87.5 \%$ \\
\hline $\begin{array}{l}\text { Noise emissions } \\
\text { standard from } \\
\text { lorries }\end{array}$ & $\mathbf{P}$ & $37.5 \%$ & $66.7 \%$ & $79.2 \%$ & $83.3 \%$ \\
\hline $\begin{array}{l}\text { Sulphur content in } \\
\text { gas oil }\end{array}$ & $\mathbf{P}$ & $12.5 \%$ & $54.2 \%$ & $70.8 \%$ & $83.3 \%$ \\
\hline $\begin{array}{l}\text { Contaminated sites } \\
\text { policy }\end{array}$ & NPP & $12.5 \%$ & $29.2 \%$ & $50.0 \%$ & $83.3 \%$ \\
\hline $\begin{array}{l}\text { Precautionary } \\
\text { principle: reference } \\
\text { in legislation }\end{array}$ & NPP & - & $8.3 \%$ & $25.0 \%$ & $79.2 \%$ \\
\hline Eco-labelling & $\mathbf{P}$ & - & $4.2 \%$ & $20.8 \%$ & $79.2 \%$ \\
\hline Eco-audit & PP & - & - & $8.3 \%$ & $75.0 \%$ \\
\hline $\begin{array}{l}\text { Heavy fuel oil levy } \\
\text { for industry }\end{array}$ & PP & $20.8 \%$ & $25.0 \%$ & $45,8 \%$ & $70.8 \%$ \\
\hline $\begin{array}{l}\text { Motorway noise } \\
\text { emissions }\end{array}$ & NPP & $8.3 \%$ & $12.5 \%$ & $41.7 \%$ & $70.8 \%$ \\
\hline $\begin{array}{l}\text { Environmental/ } \\
\text { sustainable } \\
\text { development plan }\end{array}$ & NPP & - & - & $25.0 \%$ & $70.8 \%$ \\
\hline $\begin{array}{l}\mathrm{CO}_{2} \text { emissions from } \\
\text { heavy industry }\end{array}$ & PP & - & - & $12.5 \%$ & $70.8 \%$ \\
\hline Waste landfill target & NPP & - & - & $4.2 \%$ & $66.7 \%$ \\
\hline Soil protection & NPP & $8.3 \%$ & $12.5 \%$ & $41.7 \%$ & $62.5 \%$ \\
\hline
\end{tabular}


Table 5.2 (cont.)

\begin{tabular}{llllll}
\hline \hline & $\begin{array}{c}\text { Trade- } \\
\text { related }\end{array}$ & 1970 & 1980 & 1990 & 2000 \\
\hline $\begin{array}{l}\text { Recycling } \\
\quad \text { construction waste }\end{array}$ & $\mathrm{PP}$ & - & $4.2 \%$ & $12.5 \%$ & $58.3 \%$ \\
$\begin{array}{l}\text { Waste recovery target } \\
\begin{array}{l}\text { Promotion of } \\
\text { refillable beverage }\end{array}\end{array}$ & $\mathrm{NPP}$ & - & - & $4.2 \%$ & $54.2 \%$ \\
$\quad$ containers & $\mathrm{P}$ & $12.5 \%$ & $20.8 \%$ & $29.2 \%$ & $50.0 \%$ \\
\hline $\begin{array}{l}\text { Efficient use of water } \\
\text { in industry }\end{array}$ & $\mathrm{PP}$ & $4.2 \%$ & $16.7 \%$ & $29.2 \%$ & $41.7 \%$ \\
$\begin{array}{l}\text { Electricity tax for } \\
\text { households }\end{array}$ & $\mathrm{NPP}$ & - & $8.3 \%$ & $8.3 \%$ & $37.5 \%$ \\
$\begin{array}{l}\text { Glass reuse/recycling } \\
\text { target }\end{array}$ & $\mathrm{NPP}$ & - & - & $4.2 \%$ & $37.5 \%$ \\
$\begin{array}{l}\text { Paper reuse/recycling } \\
\text { target }\end{array}$ & $\mathrm{NPP}$ & - & - & - & $37.5 \%$ \\
$\begin{array}{l}\text { Voluntary deposit } \\
\text { system beverage } \\
\text { containers }\end{array}$ & $\mathrm{P}$ & - & - & $8.3 \%$ & $20.8 \%$ \\
\hline \hline
\end{tabular}

P: Product Standard; PP: Process Standard; NPP: Non-trade-related Policy; obligatory items in bold.

trade-related and are or have become obligatory are considerably higher than for the groups characterised by lower adoption rates. Notwithstanding this general pattern, there are notable exceptions to this trend. Forest protection policies, for instance, had been adopted by all countries under investigation already by the year 1990 , although they are not directly related to trade and had never been subject to international harmonisation. ${ }^{1}$ By contrast, despite their trade-related and obligatory nature, the policies on noise emissions

1. This can be atributed to the fact that forest protection is a very old policy field already originating in earlier centuries. 
from lorries and the sulphur content of gas oil rank comparatively low in terms of adoption rates by the year 2000 .

Second, those policies characterised by an early introduction generally reveal higher adoption rates than those measures only introduced for the first time during the 1980s or 1990s. However, also for this pattern, exceptional cases can be observed. For instance, policies on the efficient use of water in industry, the promotion of refillable beverage containers or soil protection display rather low adoption rates by the year 2000 , notwithstanding the fact that they had already been introduced by 1970 . On the other hand, there are also several 'late-comers' in our sample which nevertheless had been adopted rather quickly across the countries under study. The most outstanding case refers to policies regarding the energy efficiency of refrigerators, for which the adoption rate increased from 0 per cent to 87.5 per cent between 1990 and $2000 .^{2}$

Table 5.3 offers an overview over the extent to which the twenty-four countries in our sample have adopted the forty policies over time (ranking the countries according to the number of policies adopted by the year 2000!. While the table confirms the general findings of a rather broad policy spread, we find differences across the countries under study. First, the data reveal a difference in adoption rates between countries typically known as environmental leaders (Denmark, the Netherlands, the Scandinavian-countries and Germany) and environmental laggards (led by the US, Bulgaria, Romania and Ireland).

Second, the data show that EU membership need not automatically imply that the respective countries adopt a high number of environmental policies. While a lot of the 'top adopters' are members of the EU, there are also several countries that - in spite of EU membership - rank rather low (including the 'old members' Spain

2 Japan had introduced such a policy already by 1980 , which was, however, terminated during the subsequent decade. Hence, by 1990 no country in our sample pursued a policy promoting the energy efficiency of refrigerators. 
Table 5.3 Policy adoptions over time by country (number of countries)

\begin{tabular}{|c|c|c|c|c|}
\hline & 1970 & 1980 & 1990 & 2000 \\
\hline Denmark & 1 & 13 & 23 & 39 \\
\hline Netherlands & 8 & 14 & 24 & 39 \\
\hline Finland & 9 & 16 & 23 & 37 \\
\hline Sweden & 14 & 20 & 25 & 37 \\
\hline Germany & 5 & 12 & 24 & 36 \\
\hline Norway & 2 & 9 & 24 & 35 \\
\hline Austria & 3 & 9 & 23 & 34 \\
\hline France & 6 & 11 & 22 & 33 \\
\hline Italy & 4 & 18 & 21 & 33 \\
\hline Switzerland & 5 & 13 & 25 & 33 \\
\hline UK & 6 & 11 & 19 & 32 \\
\hline Greece & 0 & 2 & 16 & 31 \\
\hline Hungary & 9 & 18 & 22 & 31 \\
\hline Japan & 13 & 20 & 20 & 31 \\
\hline Portugal & 1 & 3 & 21 & 31 \\
\hline Spain & 1 & 7 & 20 & 31 \\
\hline Mexico & 1 & 1 & 11 & 28 \\
\hline Belgium & 8 & 14 & 17 & 27 \\
\hline Poland & 1 & 4 & 12 & 27 \\
\hline Slovakia & 3 & 7 & 9 & 27 \\
\hline Ireland & 1 & 8 & 13 & 26 \\
\hline Romania & 0 & 1 & 4 & 26 \\
\hline Bulgaria & 4 & 6 & 11 & 25 \\
\hline USA & 4 & 13 & 13 & 17 \\
\hline
\end{tabular}

and Ireland]. ${ }^{3}$ This development can be traced to the fact that a considerable part of the policies under investigation is not subject to European harmonisation.

${ }^{3}$ A similar statement applies to Belgium. In this case, however, the strong decentralisation of environmental policy competencies to the regional level has to be taken into account, implying that the number of policy adoptions at the federal level remain at a lower level. This argument might also account for the rather weak performance of the US. 
Third, we observe different dynamics regarding the change of adoption rates over time. Hardly surprising in this context are the strong increases in policy adoptions during the 1990s in the CEE countries and Mexico, which reflect the overall processes of economic catching-up and political transformation taking place in these states. An exception to this pattern is Hungary, which belonged to the group of 'top adopters' already during the first two decades of the observation period. In contrast to the pattem of strongly increasing adoption rates over time, we also find countries where policy adoption is characterised by rather low growth rates and even stagnation (examples are the US and Japan for the periods of the 1980 s and 1990s/ or a rather linear increase in policy adoptions over time [Denmark, the Netherlands, Finland, Sweden, Germany].

\subsubsection{Illustration of different spreading patterns: adoption curves}

In addition to these general aspects regarding the adoption rate levels of the policies under study, there are distinctive patterns characterising the spreading of policies and countries over time. To illustrate the latter, we will have a closer look at adoption curves of selected policy items. More specifically, we differentiate between three general empirically observable adoption patterns, namely, policies characterised by widespread adoption in the beginning of the observation period, policies characterised by a rather linear spreading process over the whole observation period, and policies where adoption took off towards the end of the observation period. We chose six examples for each pattern, thus analysing the respective developments for eighteen out of the forty environmental policies under study.

Figure 5.1 shows the adoption curves for six policies which were spreading broadly across the countries under study already during the 1970s, including the regulation of passenger car emissions, forest protection, noise emission from lorries, hazardous substances in detergents, lead in petrol and sulphur content in gas oil. All of 


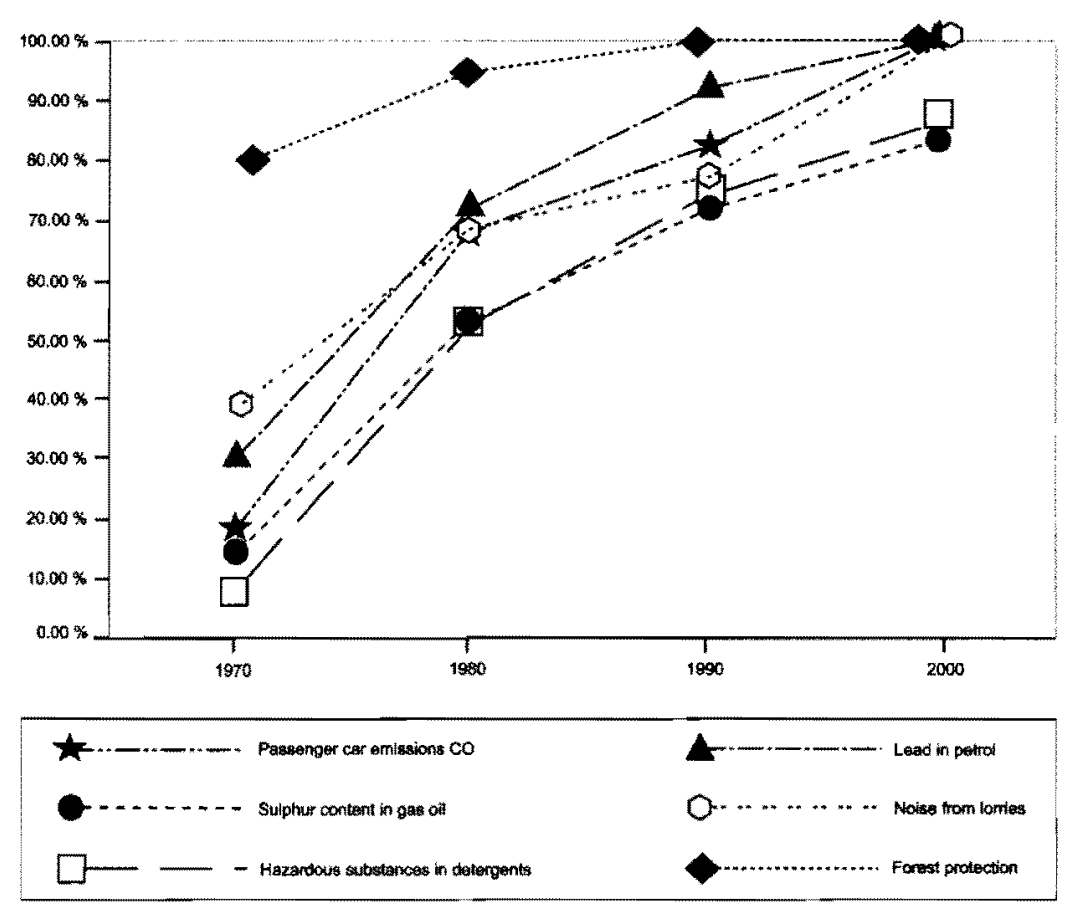

Figure 5.I Environmental policies: early adoptions, 1970-2000

these policies have in common that, while their adoption curves rise permanently over time, the numbers of adoptions were particularly high in the beginning of the observation period and, due to saturation effects, gradually decreased over time. Three policies [passenger car emissions, lead in petrol, forest protection] reach a spread of 100 per cent by the year 2000 , implying full convergence in terms of policy presence. For the three remaining policies /hazardous substances in detergents, lorry noise emissions and sulphur content in gas oill, the respective adoption rate is around 85 per cent.

In contrast to the above-mentioned development of early diffusion, figure 5.2 shows adoption curves for six policies which are characterised by a relatively linear spreading pattern. A similar development can be observed for the policies on airborne emissions from large combustion plants and on the quality of bathing water. 


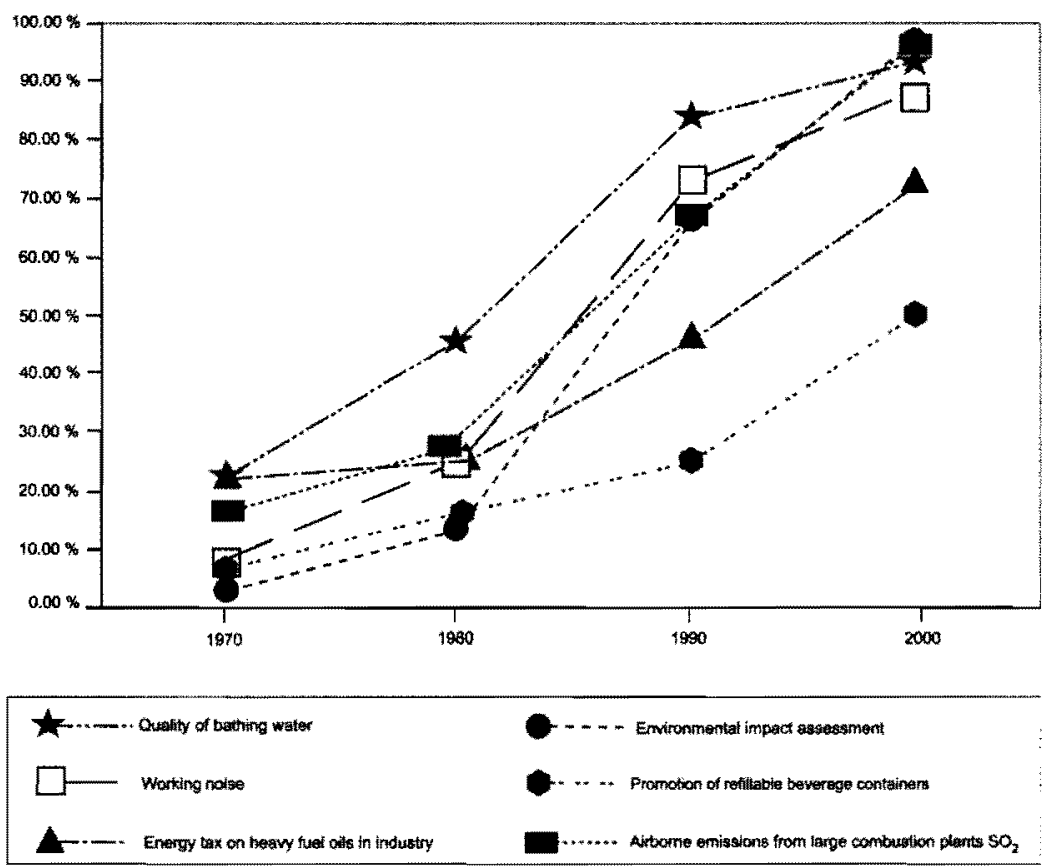

Figure 5.2 Environmental policies: linear adoptions, 1970-2000

While only few countries had adopted such policies by 1970 , almost all of the countries under investigation followed the early adopters over the observation period. The number of new adoptions is distributed rather equally over time, implying a linear shape of the adoption curve. Also the policies on noise emissions at workplaces and environmental impact assessment share a rather similar adoption path. In these cases, however, it becomes apparent that a rather linear spreading process took off only from 1980 onwards, nevertheless leading to a high adoption rate and hence degree of convergence by the year 2000 . Steadily increasing numbers of adoptions are also observed for policies on the promotion of refillable beverage containers and on the introduction of levies on the industrial use of heavy fuel oil, although in these cases, adoption rates and convergence remain at a lower level when compared to the other cases. 


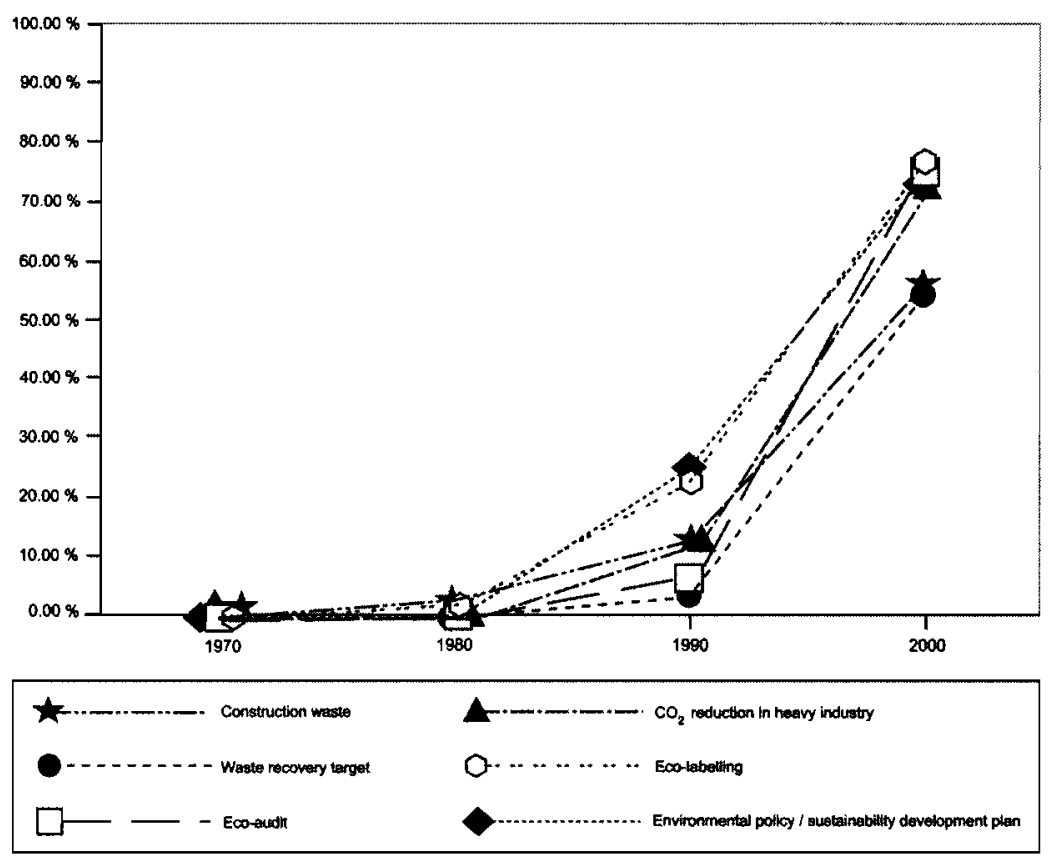

Figure 5.3 Environmental policies: late adoptions, 1970-2000

Finally, six environmental policies that are characterised by a late rather than early or linear process of diffusion are presented in figure 5.3. Notwithstanding their only recent emergence, they have been adopted by a large number of countries within a comparatively short period of time. For example, eco-labels, eco-audits and national environmental plans were reported for less than a quarter of the twenty-four countries by 1990 . In 2000 , they had spread to over 70 per cent. The same applies to policies on the reduction of $\mathrm{CO}_{2}$ emission in heavy industries that are found in seventeen countries by 2000 . In the latter case, only Austria, Finland and Sweden had adopted such measures in 1990. Similar figures are found for policies on construction waste and on waste recovery targets.

One could certainly argue that the impressive spread of these measures can be traced to respective harmonisation activities at the EU level. This scenario, however, only applies to three out of 
the six policies listed, namely the eco-label (EU directive in 1992), the eco-audit (EU regulation in 1993) and waste targets (EU directive in 1994). European harmonisation thus cannot fully account for the sharp increase in adoption rates during the 1990 s.

The aggregate analysis of policy convergence with regard to policy presence indicates several general developments. First, changes in rates of policy adoption reveal a picture of strongly growing policy similarity over time. Second, while this statement holds for the whole policy sample, convergence is particularly pronounced for policies that share one or more of the following characteristics: trade-relatedness, obligatory nature and early introduction. Third, three different patterns of adoption can be identified, including processes of early, linear and late cross-national spreading of policies. Fourth, differences exist with regard to country-specific adoption patterns. In this context, our empirical findings confirm generally made distinctions between environmental leader and laggard countries.

\subsection{CONVERGENCE OF POLICY INSTRUMENTS}

Depending on the underlying indicators, judgements on the occurrence or non-occurrence of policy convergence can be based on different policy dimensions. One option is to investigate the convergence on the basis of the mere presence of certain policies (as done in the previous section). This implies the application of a very broad conception of policy convergence, because convergence on that dimension need not imply that countries also converge with regard to the use of respective instruments. In this section, we focus on this latter policy dimension, hence applying a more demanding indicator for assessing cross-national convergence. While convergence of instruments coincides with convergence of policies (to converge on instruments, countries must have a relevant policy in place), countries using similar instruments might still reveal considerable differences with regard to the settings of each instrument.

When analysing the convergence of policy instruments, the focus is on the question whether different countries apply the same 
means to reach their policy goals. Convergence of instruments occurs if one instrument type (e.g., obligatory standard, tax or levy, information-based instruments or planning instruments) is preferred to others across countries.

\subsubsection{General patterns}

To provide an overview of the relative importance of policy instruments for the different policy items under study, table 5.4 contains the distribution of frequencies for each of the eleven instrument types that have been distinguished in the context of the underlying project. In this regard, the data presented below refer to information on what has been identified as the dominant instrument by national environmental policy experts. Thus, the data do not refer to the entire repertoire of instruments that could be found in a country, but only to a pre-structured distinction of instrument types that can be considered as the most important in the environmental field and that have also been identified in other analyses (cf. Holzinger, Knill and Schäfer 2003).

When analysing the distribution of dominant instruments in closer detail, several general developments can be identified. First, the data reveal that the overall repertoire of the adopted instruments is rather broad, including all of the eleven instrument types under study. Second, there is strong variation with regard to the relative importance of different instrument types over time.

In this context, obligatory standards constitute the instrument type most frequently reported as the dominant one. The number of obligatory standards as dominant instrument type with respect to a certain policy steadily increased over time, from 45 observations in 1970 up to 128 for the year 2000 . This general judgement on the dominance of obligatory standards is somewhat modified, however, if we look at the share of this instrument type relative to other types. Taking into account the general cross-national spread of environmental policies during the investigation period, we find a decreasing share of obligatory standards relative to other policy 


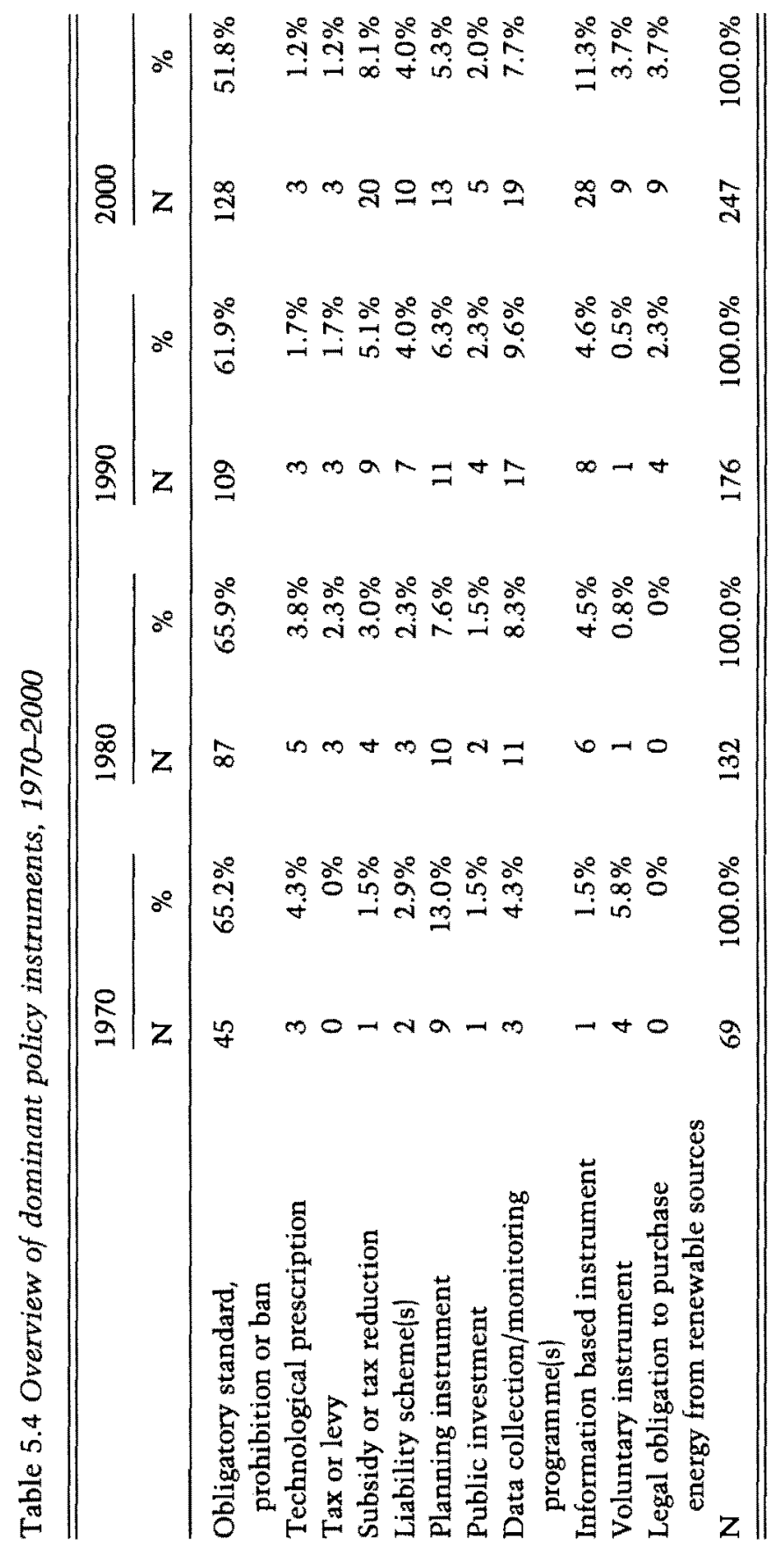


instruments that had already started during the 1980s. Whereas in 1980,66 per cent of all dominant instruments were obligatory standards, this share decreases to 52 per cent in 2000. A similar decrease in importance can be observed for planning instruments, the second most popular dominant instrument type at the beginning of the observation period in 1970 .

By contrast, the relative importance of so-called NEPIs, such as information-based or monitoring instruments, slightly increases during the 1990s. The same holds true for economic instruments like subsidies and taxes. However, the only slight increase in importance is in strong contrast to political statements which emphasise the increasing relevance of new instruments (for similar findings see, for instance, Holzinger, Knill and Schäfer 2003; Jordan, Wurzel and Zito 2003). Moreover, the relatively low importance of other instruments that are also subsumed under the heading of new instruments might be traced to the fact that some of them are only relevant for certain policy items, for example liability schemes (contaminated sites), voluntary agreements $\left(\mathrm{CO}_{2}\right.$ emissions from heavy industry) or legal obligation to purchase energy from renewable sources. Finally, public investment plans or technological prescriptions are not commonly used as dominant instruments in our sample, which does not mean that they could not be used in addition to other policy instruments.

\subsubsection{Illustration of different adoption patterns}

To illustrate different patterns of convergence in the use of policy instruments, we have selected three examples. In the first case, the regulation of industrial discharges into the surface water, we observe one instrument type developing into the single dominant approach over time. The second example refers to instruments that are applied to promote the use of energy from renewable sources. Instead of a development towards one dominant instrument, this case is characterised by the emergence of two dominant approaches over time. Finally, in the third example, the reduction of $\mathrm{CO}_{2}$ emissions from heavy industry, a diversification rather than concentration in 
the adoption of dominant policy instruments takes place, hence indicating patterns of divergence rather than convergence in instrument repertoires.

Figure 5.4 shows the repertoire of dominant policy instruments reported for each country for the regulation of industrial emissions of zinc into the surface water. Apparently, from 1970 to 2000, obligatory standards developed into the most commonly used policy instrument for the regulation of industrial discharges. Out of five different instrument types including technological prescriptions, planning instruments, information-based instruments and taxes or levies), obligatory standards are the only remaining dominant

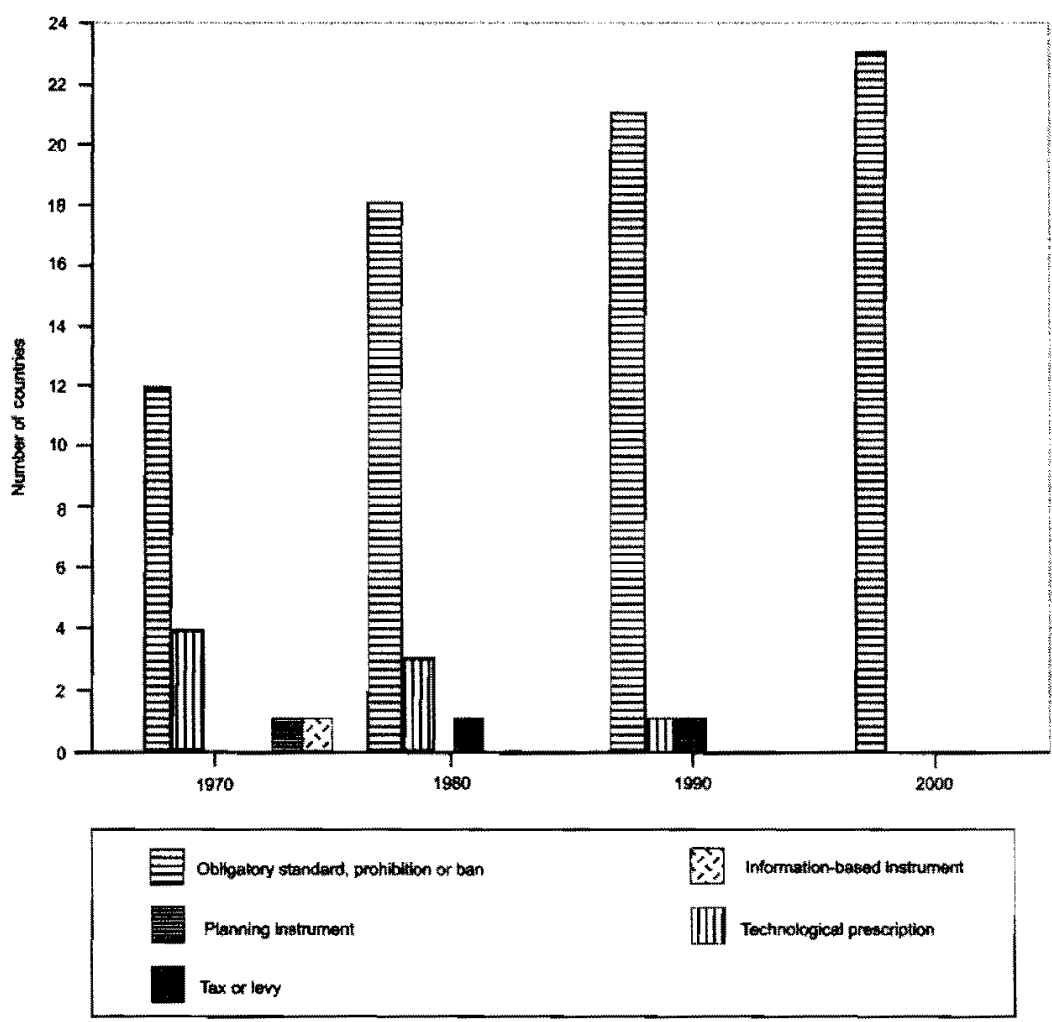

Figure 5.4 Policy instruments: industrial discharges of zinc into the surface water 
instrument reported in 2000. The variation of the instrument repertoire across countries is thus clearly reduced.

A different pattern can be observed for dominant instrument types that are applied to promote the use of energy from renewable sources (figure 5.5). This example refers to a rather recent policy innovation in the environmental field. It is only from the mid1980s onwards that policies to promote the production and use of energy from renewable sources have started to spread across countries. Since that time, however, instruments to promote renewable energy have been widely adopted. In 2000, twenty-two out of the twenty-four countries under study had introduced such measures.

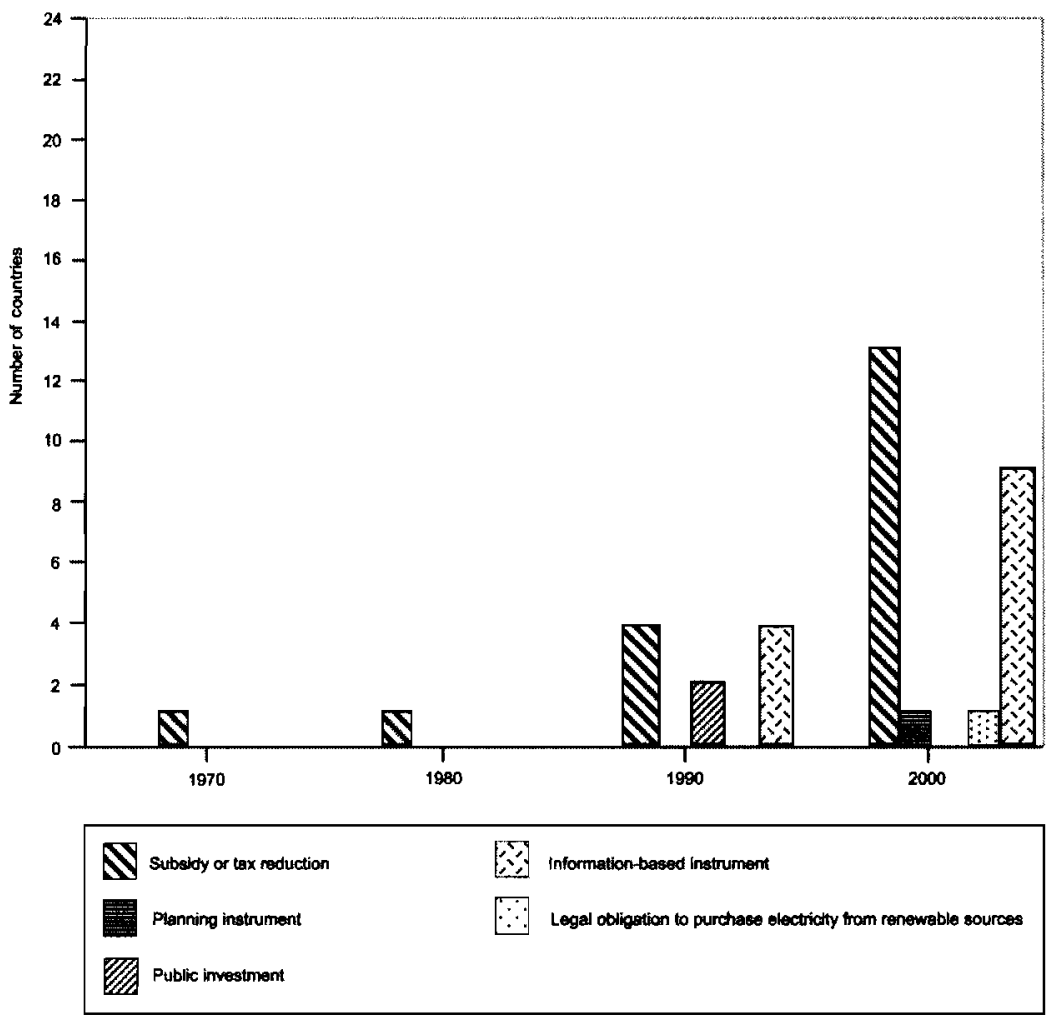

Figure 5.5 Policy instruments: electricity from renewable sources 
In 2000, two approaches have emerged as most commonly applied instruments. The first approach refers to subsidies or tax reductions for producers of renewable energy. While Finland relied on this approach already in 1970 , the number of countries applying this instrument as the dominant national approach to promote renewable energy rose to eleven in 2000 . The second approach is the reliance on legal obligations for energy users to purchase a certain amount of renewable energy. This instrument has been applied in four countries by the year 1990 /Germany, Greece, the Netherlands and the UK), with the number of countries following this approach rising to nine in 2000. Apart from these two dominant approaches, other instruments are of minor importance. In 1990, two countries (Austria and Poland) predominantly relied on public investment for the promotion of renewable energy. Both countries switched to legal purchasing obligations by 2000 . In addition, two other instruments have been reported as dominant approaches in 2000, namely information-based and planning instruments. Both are of very limited relevance, as they are applied as dominant instruments only in Switzerland and in France. In view of this constellation, we thus find convergence towards two different instrument types.

In contrast to the above-mentioned examples, patterns of adoption indicate a less clear picture of convergence with regard to dominant instruments applied to reduce $\mathrm{CO}_{2}$ emissions from heavy industry (figure 5.6). Prior to 1990, only three countries had adopted a relevant policy, relying on different instruments to achieve their policy objectives. The adoption of data collection and monitoring programmes in Austria was paralleled by the use of planning instruments in Sweden and the introduction of tax schemes in Finland. By the year 2000, seven further countries had introduced such policies. While France, Germany, Ireland, Norway, Switzerland and the UK primarily rely upon the use of voluntary instruments, the Netherlands applies tax reduction schemes, hence following the approach of Finland. 

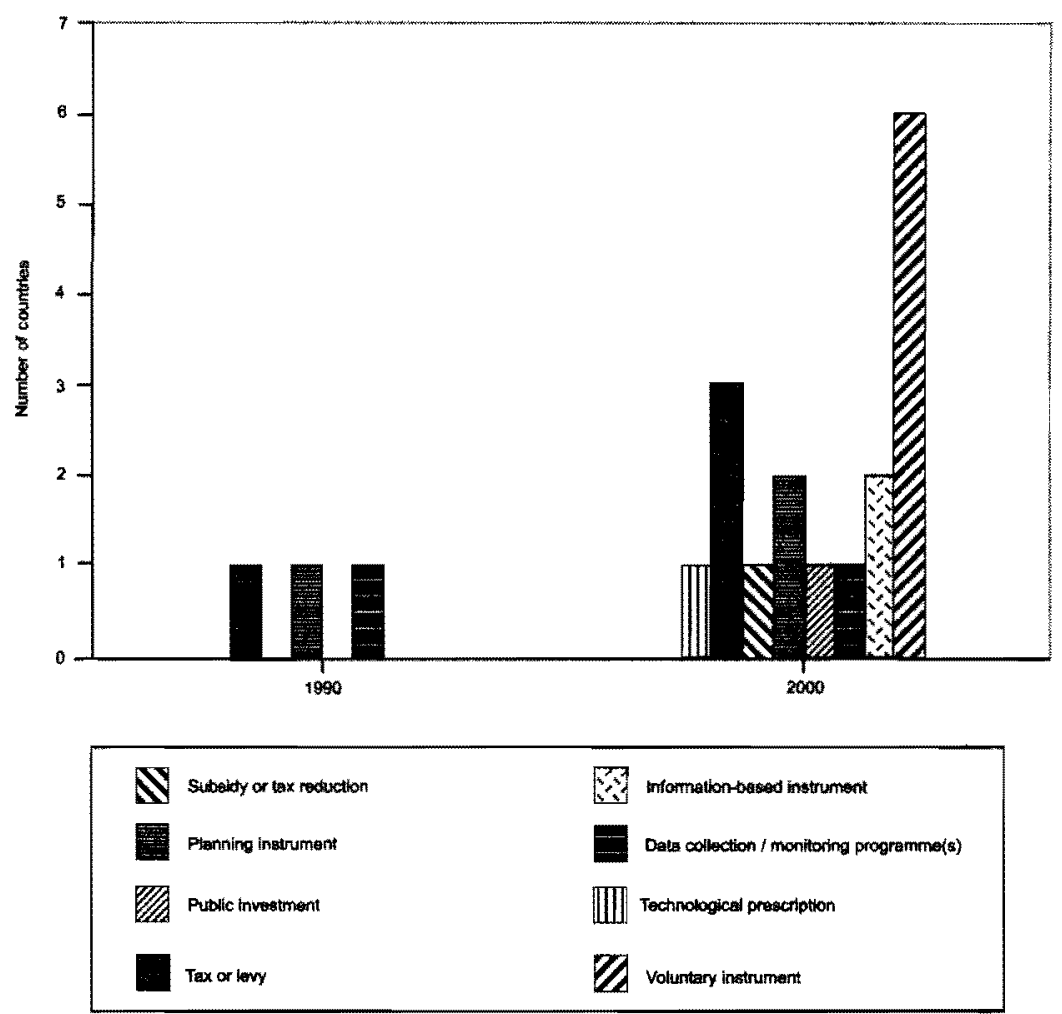

Figure 5.6 Reduction of $\mathrm{CO}_{2}$ emissions from heavy industry

Although it is obvious that one instrument type is dominantly applied across countries, statements about convergence are difficult to make on the basis of the underlying frequency analysis. This can be traced to the fact that the emergence of voluntary instruments as a dominant instrument coincides with an expansion of the repertoire of dominant instruments applied across countries. While for 1990 , only three instrument types were reported, their number rose to seven by the year 2000 .

In sum, our analysis of cross-national convergence on the dimension of environmental policy instruments indicates a less clear trend towards similarity increases over time than is the case when the focus is solely on the presence of policies. While absolute 
figures point to the increasing dominance of obligatory standards, the growing use of other instruments over time modifies this picture. This ambivalent statement is underlined by the illustration of different convergence patterns, including cases in which we observe the emergence of one or two dominant instruments over time, but also constellations characterised by a growing diversification of instruments.

\subsection{CONVERGENCE OF POLICY SETTINGS}

In contrast to the analysis of convergence in terms of policy presence and policy instruments, it is only for policies which define a concrete setting, i.e., an environmental standard or tax, that we can complement the analysis of changes in variation (sigma-convergence) with an analysis of changes in the regulatory mean. While the study of the degree and direction of convergence constitutes the first step of the following analysis, we will complement these findings by interpreting our results in the light of alternative concepts of beta- and gamma-convergence.

\subsubsection{Sigma-convergence and mean changes}

In a first step, we look at the changes of the variation coefficient for the whole group and different sub-groups of the twenty-one setting items analysed in our research project. The coefficient of variation $|\mathrm{CV}|$ is defined as

$$
C V=\frac{\frac{1}{N} \sqrt{\sum_{i=1}^{N}\left(X_{i}-\bar{X}\right)^{2}}}{\bar{X}},
$$

with $N$ referring to the number of countries, $X_{i}$ constituting the relevant policy setting of country $i$ and $\bar{X}$ being the arithmetic mean across the country sample. The results of this analysis are summarised in table 5.5 .

To assess the convergence of setting items along these lines, two perspectives are distinguished. According to the first perspective, 
Table 5.5 Variation coefficients for setting items

\begin{tabular}{lccccc}
\hline \hline & 1970 & 1980 & 1990 & 2000 & $\begin{array}{c}\text { No. of } \\
\text { policies }^{a}\end{array}$ \\
\hline All settings & 0.58 & 0.73 & 0.72 & 0.68 & 21 \\
Countries with policy from 1980 & & 0.73 & 0.85 & 0.67 & 21 \\
Countries with policy from 1990 & & & 0.70 & 0.62 & 21 \\
\hline Product-related settings & 0.20 & 0.38 & 0.69 & 0.72 & 6 \\
Countries with policy from 1980 & & 0.38 & 0.69 & 0.53 & 6 \\
Countries with policy from 1990 & & & 0.69 & 0.64 & 6 \\
\hline Production-process-related & 0.96 & 1.00 & 0.79 & 0.79 & 9 \\
$\quad$ settings & & & & & \\
Countries with policy from 1980 & & 0.84 & 0.88 & 0.68 & 9 \\
Countries with policy from 1990 & & & 0.80 & 0.64 & 9 \\
\hline Non-product-/process-related & 0.38 & 0.72 & 0.63 & 0.48 & 6 \\
$\quad$ settings & & & & & \\
Countries with policy from 1980 & & 0.76 & 0.87 & 0.71 & 6 \\
Countries with policy from 1990 & & & 0.65 & 0.63 & 6 \\
Obligatory settings & 0.10 & 0.43 & 0.64 & 0.66 & $3 / 8 / 11 / 12$ \\
Countries with policy from 1980 & & 0.43 & 0.72 & 0.51 & $3 / 8 / 11 / 12$ \\
Countries with policy from 1990 & & & 0.67 & 0.52 & $3 / 8 / 11 / 12$ \\
\hline Non-obligatory settings & 0.72 & 0.97 & 0.84 & 0.71 & $18 / 13 / 10 / 9$ \\
Countries with policy from 1980 & & 0.86 & 0.93 & 0.83 & $18 / 13 / 10 / 9$ \\
Countries with policy from 1990 & & & 0.82 & 0.85 & $18 / 13 / 10 / 9$ \\
\hline \hline
\end{tabular}

Note:

${ }^{a}$ The respective numbers for obligatory and non-obligatory policy items vary over the investigation period, as over time more and more policies became subject to international or supranational regulation. The respective numbers given in the outer right column refer in their order to the four decades distinguished in the table.

for each point in time, all available values are included (implying that the number of countries might change over time): regarding $x$ countries in $t_{i}$ and $y$ countries in $t_{j}$, is there a decrease in variation over time? This way, it is possible to show how countries that introduced a policy in a certain period contributed to convergence or divergence (perspective 1). In the second perspective, by contrast, 
only those countries are included in the analysis for which a value existed in $t_{i}$, that is, the number of countries is held constant throughout the observation period (perspective 2).

First, when looking at the average variation coefficient for all twenty-one setting items from perspective 1 , the figures show that convergence only occurred during the period from 1990 to 2000. Moreover, the similarity increase remains rather low, with the variation coefficient shifting from 0.72 to 0.68 . Perspective 2 reveals that those countries having introduced a policy by 1980 further diverged during the following decade. Moreover, from perspective 2 , the convergence development during the 1990 s is more pronounced, indicating that countries which introduced a policy after 1990 converged to a lesser degree towards all others than those countries which had already adopted a relevant regulation before that time. In combination with stable coefficients in perspective 1 , this means that those countries adopting new policies during the 1980 s oriented themselves more strongly towards the policy in specific countries (i.e., the frontrunner states).

Second, we can compare the development of the variation coefficient for setting items that refer to trade-related policies (i.e., product or production standards) and policies that are not subject to competitive pressures emerging from economic integration. Our findings reveal patterns that are striking from the perspective of theories of regulatory competition. So, the variation coefficients indicate divergence rather than convergence for product standards. For production standards, weak convergence trends can only be observed during the 1980s. By contrast, increases of similarity are reported for policies that are not related to trade; the difference between perspective 1 and perspective 2 shows that this is mainly caused by countries that adopted a limit value after 1990 . This finding is in contradiction with expectations derived from theories of regulatory competition, stating that convergence tendencies through mutual adjustment of national policies should be more pronounced in policies subject to competitive pressures through economic integration. 
Third, variation coefficients for the sub-groups of setting items can be compared for obligatory and non-obligatory policies. Also in this case, empirical findings seem to be contradictory with the expectation that convergence for obligatory items should be more pronounced than for non-obligatory items. While there is convergence for non-obligatory items since 1980, the picture looks quite different for obligatory items. While perspective 1 even suggests divergence, perspective 2 reveals convergence only for the period between 1990 and 2000 for those countries that had established a relevant policy either in 1980 or 1990 . This general statement holds regardless of the fact that absolute coefficient values for obligatory items are generally lower than those for non-obligatory items.

Table 5.6 provides an overview of the development of variation coefficients (on the basis of perspective 1) and changes of the regulatory mean for all twenty-one setting items under investigation. On the basis of these data, several general developments become apparent. First, the changes in the variation coefficients underline the above finding of rather limited sigma-convergence. While for the 1970s and the 1980s there is an overall, generally rather slight, increase of variation, the period of the $1990 \mathrm{~s}$ is characterised by a highly mixed pattern including cases of strong convergence as well as strong divergence. Moreover, the partially surprising differences in similarity changes for the varying policy types again become apparent. In this context, we also observe that the similarity changes for non-trade-related policies in general are characterised by less volatile patterns than is the case for product or process regulation.

Second, we find partially strong differences in convergence patterns within the different policy sub-groups. With respect to product standards, cases of strong convergence during the 1990s for passenger car emission standards coincide with constellations of strong divergence during the same period (lead in petrol, sulphur content of gas oil). Similarly opposite trends can also be found for process standards. These differences seem to be largely unaffected 


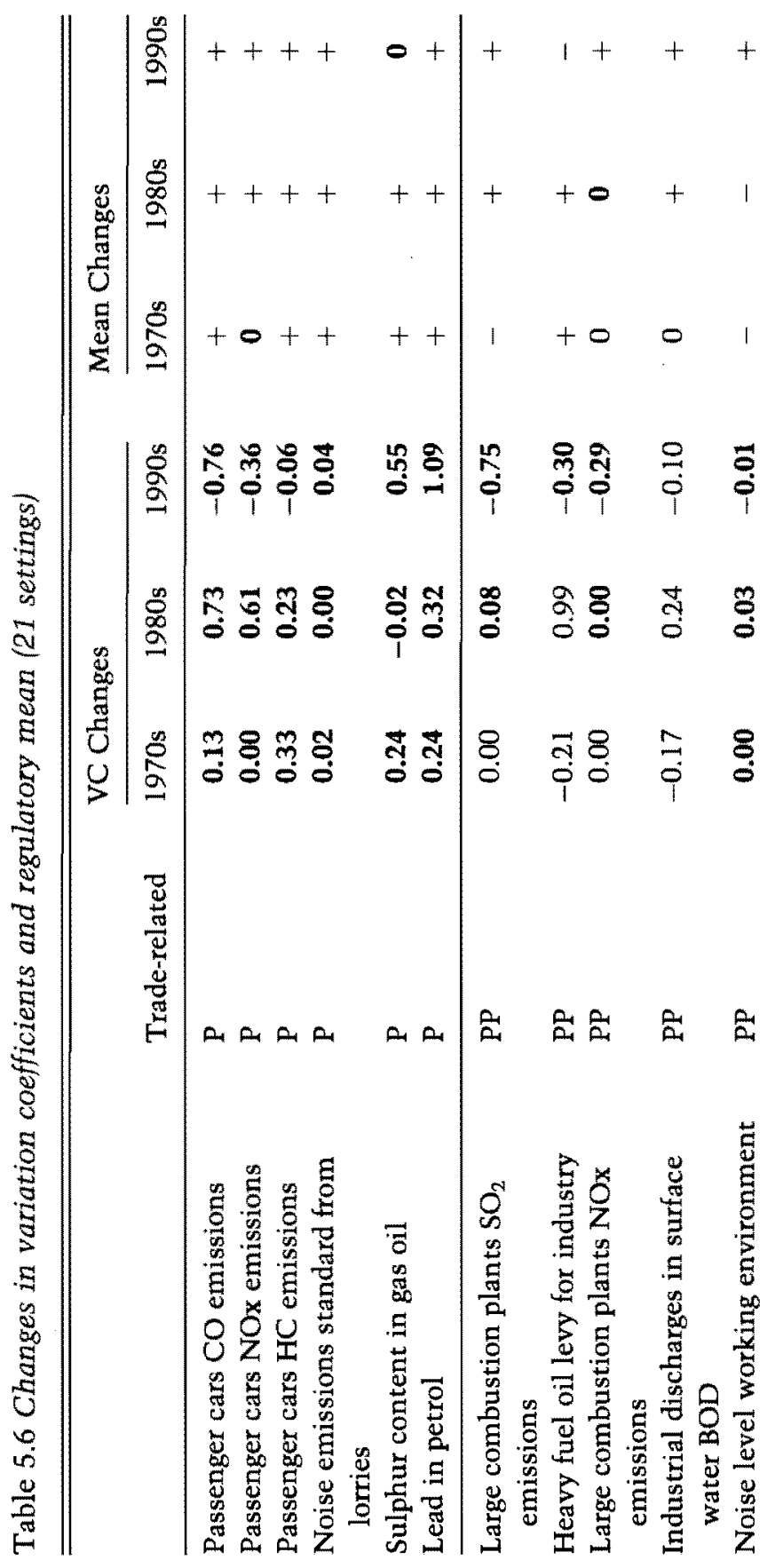




$$
\begin{aligned}
& \begin{array}{ll|l|l||}
++1++ & +1+0 & 0 & 1 \\
+++++ & 1 & 0 & 0
\end{array} \\
& +++++11000 \\
& \text { 苛 }
\end{aligned}
$$

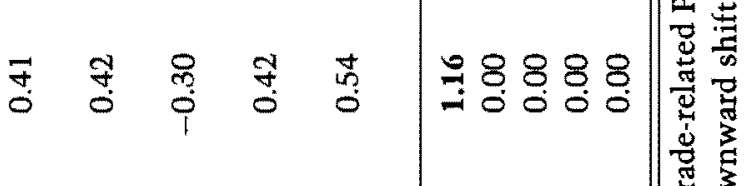

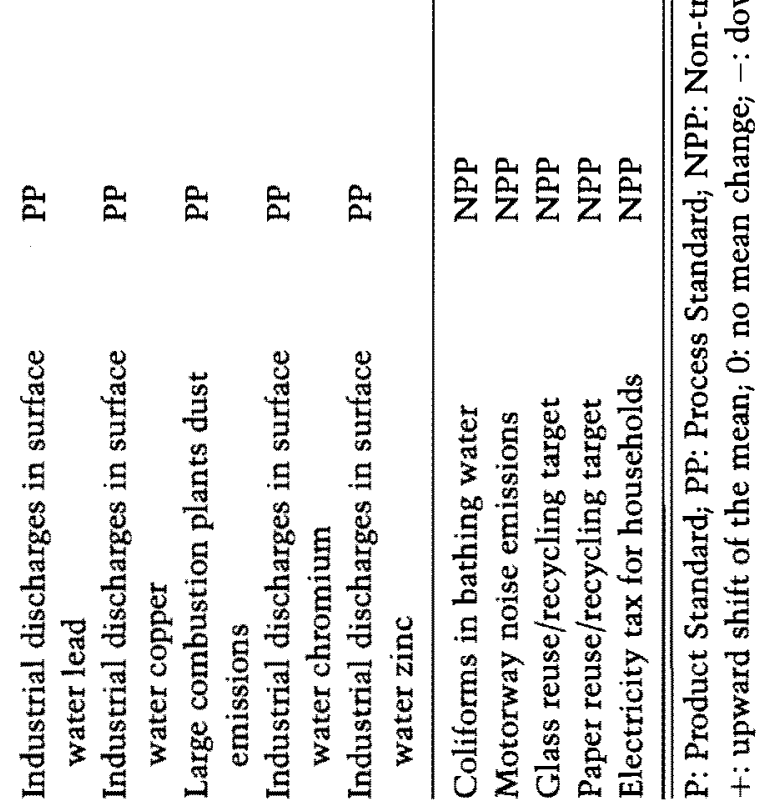


by the extent to which the policies are obligatory or non-obligatory in nature. ${ }^{4}$

Third, with regard to the direction of convergence, our empirical findings indicate a general trend towards increasing regulatory strictness over time. This pattern is most pronounced for product standards, for which an average strengthening of standards can be observed throughout the whole observation period. This development, with minor and periodical exceptions, also holds for production standards. Hence, our findings provide no support for the race-to-the-bottom scenarios developed in theories of regulatory competition. While the picture is rather unclear for most of the non-trade-related policies, the regulation of coliforms in bathing water seems to reflect a case of a race-to-the-bottom, with a weakening of the regulatory mean throughout the whole observation period. $^{5}$

\subsubsection{Beta-convergence}

The concept of beta-convergence is applied in particular in studies on economic convergence. Beta-convergence occurs when poor economies grow faster than rich ones. It often goes along with sigma-convergence, as 'growing together' presupposes a process of catching-up. However, we can also conceive of constellations in which catching-up may entail overtaking and thus a greater dissimilarity than before, hence implying sigma-divergence (Heichel,

\footnotetext{
* As already mentioned in chapter 4 above, we have no product standards in our sample that are not subject to international or supranational harmonisation, imply. ing that all product items are marked as obligatory. This does not mean, however, that they are obligatory for all countries under study, given their variance in membership in international and supranational institutions.

${ }^{5}$ The major reason for this development is that the rather strict standards of the early adopters Sweden and Finland were followed by a much weaker standard defined at the level of the EU that had subsequently to be implemented by the member states. As the countries with stricter limit values did not depart from their regulatory levels, the decreases in the regulatory mean reflect no race-to-the-top, but result from the fact that new adopters introduced less demanding standards as the early innovators. This development is due to high scientific uncertainty in this matter.
} 
Pape and Sommerer 2005; Sala-i-Martin 1996: 1022f.). The concept of beta-convergence can also be applied to the study of policy convergence (see chapter 4). In this context, the growth rate of an economy is substituted by the change rate of a policy setting.

Beta-convergence offers a complementary view to the study of convergence in general, as it includes the dynamics of policy changes across countries. However, the concept as such provides no sufficient basis to make an overall judgement on policy convergence. Betaconvergence does not directly refer to the absolute level of the respective policy, nor does it include a measurement of the relative position of a country's policy towards the rest. ${ }^{6}$

To provide an overview of the extent to which we can observe beta-convergence for the twenty-one policy settings under study [see table 5.7), we estimate beta-convergence on the basis of the following bivariate regression:

$$
\Delta s_{i, t_{0}-t_{1}}=c+\beta\left(s_{i, t_{0}}\right)+e_{i, t_{0}}
$$

where $\Delta s_{1}$ refers to the change rate of a policy setting between $t_{0}$ and $t_{1}, c$ is the constant, $s_{i, t_{0}}$ is the initial level of regulation of the respective setting and $\mathrm{e}_{\mathrm{i}, \mathrm{t}_{0}}$ the error term. The standardised coefficients/scale from -1.00 to 1.00 ) are given in table 5.7. A positive coefficient is equivalent to a process of catching up where countries with formerly lax regulations have higher change rates for their policies than their counterparts with stricter regulations.

The findings reveal an overall pattern of beta-convergence. For most of the policy settings, a process of catching up can be observed. In these cases, countries with less stringent environmental regulations strengthened their policies to a higher degree than former frontrunner countries. It is only for six items that we find betadivergence, albeit not for the whole observation period. The latter process is indicated by a negative coefficient in table 5.7 . For $\mathrm{CO}$

${ }^{6}$ Further criticisms on the concept of beta-convergence referring to the insufficient inclusion of cross-country dynamics are developed by Boyle and McCarthy (1999). 
Table 5.7 Beta-convergence (21 settings)

\begin{tabular}{|c|c|c|c|c|}
\hline & $\begin{array}{l}\text { Trade- } \\
\text { related }\end{array}$ & $1970 \mathrm{~s}$ & $1980 \mathrm{~s}$ & $1990 \mathrm{~s}$ \\
\hline Passenger cars HC emissions & $\mathrm{P}$ & 1.00 & 0.87 & 1.00 \\
\hline Passenger cars $\mathrm{CO}$ emissions & $\mathrm{P}$ & -1.00 & 0.69 & 1.00 \\
\hline Passenger cars NOx emissions & $\mathrm{P}$ & - & 0.47 & 1.00 \\
\hline Lead in petrol & $\mathrm{p}$ & -0.23 & 0.57 & 0.60 \\
\hline Sulphur content in gas oil & $\mathbf{p}$ & 1.00 & 0.98 & 0.35 \\
\hline $\begin{array}{l}\text { Noise emissions standard from } \\
\text { lorries }\end{array}$ & $\mathrm{P}$ & 0.66 & 0.44 & -0.08 \\
\hline Heavy fuel oil levy for industry & $\mathrm{PP}$ & 0.60 & 0.13 & 1.00 \\
\hline $\begin{array}{l}\text { Large combustion plants } \mathrm{SO}_{2} \\
\text { emissions }\end{array}$ & $\mathrm{PP}$ & - & -1.00 & 0.99 \\
\hline $\begin{array}{l}\text { Large combustion plants dust } \\
\text { emissions }\end{array}$ & PP & 1.00 & 0.98 & 0.88 \\
\hline $\begin{array}{l}\text { Large combustion plants NOx } \\
\text { emissions }\end{array}$ & $\mathrm{PP}$ & - & - & 0.83 \\
\hline $\begin{array}{l}\text { Industrial discharges in surface } \\
\text { water lead }\end{array}$ & PP & - & 1.00 & 0.53 \\
\hline $\begin{array}{l}\text { Industrial discharges in surface } \\
\text { water chromium }\end{array}$ & PP & 1.00 & 1.00 & 0.48 \\
\hline Noise level working environment & PP & - & - & 0.39 \\
\hline $\begin{array}{l}\text { Industrial discharges in surface } \\
\text { water zinc }\end{array}$ & PP & - & 0.32 & 0.38 \\
\hline $\begin{array}{l}\text { Industrial discharges in surface } \\
\text { water copper }\end{array}$ & PP & - & 0.99 & 0.33 \\
\hline $\begin{array}{l}\text { Industrial discharges in surface } \\
\text { water BOD }\end{array}$ & PP & - & -0.03 & -0.10 \\
\hline Coliforms in bathing water & NPP & - & 0.61 & 0.27 \\
\hline Motorway noise emissions & NPP & - & - & 0.04 \\
\hline Electricity tax for households & NPP & - & -1.00 & -1.00 \\
\hline Glass reuse/recycling target & NPP & - & - & - \\
\hline Paper reuse/recycling target & NPP & - & - & - \\
\hline
\end{tabular}

P: Product Standard; PP: Process Standard, NPP: Non-trade-related Policy; obligatory items in bold. 
emissions from passenger cars, for instance, a negative sign is given for 1970s only. During this decade, two pioneer countries, the US and France, diverged. Compared to its initial level, the American standard was strengthened in a much stronger way than was the case for the respective French limit value.

\subsubsection{Gamma-convergence}

While the concept of beta-convergence allows us to identify processes of catching up between leaders and laggards, we still have no information on the extent to which the countries actually changed their ranks in terms of regulatory strictness over time. This can be traced to the fact that catching up need not necessarily mean overtaking. To grasp the latter aspect, the concept of gammaconvergence has been developed. This way, gamma-convergence offers complementary information about the overall trend of observed sigma-convergence. For instance, we might interpret a process of growing together that coincides with a complete overthrow of country rankings differently than a situation in which national limit values become similar over time, but with pioneer and laggard countries holding their rank positions. Moreover, in addition to the identification of changes in country rankings / that are not covered by beta-convergence), gamma-convergence also allows us to detect policy changes which are not perceived when relying on sigma-convergence, as country rankings may change, for example, without a significant decrease in cross-country variation.

For the analysis of gamma-convergence, country rankings based on the strictness of domestic policies are compared over time. For instance, if countries with strict environmental regulations in the first ranks fall behind over time, gamma-convergence occurs. Policy change is assessed with the gamma coefficient, a simple measure of correlation for ordinal scales based on the calculation of rank concordance for two points in time. Thus, we speak of gammaconvergence if the ranking in $t_{0}$ is not associated with the ranking 
in $t_{1}$. The gamma coefficient is based on differences between concordant pairs $(p)$ and discordant pairs $[q]$ and computed as

$$
\gamma=\frac{(p-q)}{(p+q)}
$$

with a scale from -1.00 to 1.00 . The more values we find below 1.00 , the higher the mobility of countries over time and hence gamma-convergence.

Table 5.8 shows the correlation of country rankings for all twenty-one setting items. First, it becomes apparent that there are only two policy items (the recycling targets for glass and paper reuse) for which no changes in country rankings occurred throughout the whole observation period. This can mainly be traced to the fact that in these cases no policy adoptions occurred during the first half of the observation period. For all other items, we observe in part far-reaching changes, including two policies with relatively high mobility for all decades, namely, limit values for lead in petrol (gamma between .36 and .69) and noise emission from lorries (gamma between .45 and .77).

Second, the table reveals that mobility changes are considerably higher for trade-related policies, while gamma-convergence for policies that are not related to trade is rather low. This statement holds for the whole observation period.

Third, we find different convergence movements across the policies under investigation. For some policies, gamma-convergence occurred primarily at the beginning of the observation period (e.g., limit values for the sulphur content in gas oil). Other cases, by contrast, reveal an opposite pattern, with gamma-convergence being most pronounced throughout the 1980s and 1990s le.g., the regulation of industrial discharges into surface water!.

\subsubsection{Comparative assessment for different convergence concepts}

The concepts of sigma-, beta- and gamma-convergence analyse and evaluate cross-national policy change on the basis of different 
Table 5.8 Gamma-convergence (21 settings)

\begin{tabular}{|c|c|c|c|c|}
\hline & $\begin{array}{l}\text { Trade- } \\
\text { related }\end{array}$ & $1970 \mathrm{~s}$ & $1980 \mathrm{~s}$ & $1990 \mathrm{~s}$ \\
\hline Passenger cars $\mathrm{CO}$ emissions & $\mathbf{p}$ & 0.95 & 0.76 & 0.33 \\
\hline Lead in petrol & $\mathbf{P}$ & 0.56 & 0.69 & 0.36 \\
\hline Passenger cars $\mathrm{NOx}$ emissions & $\mathrm{P}$ & 1.00 & 0.70 & 0.45 \\
\hline $\begin{array}{l}\text { Noise emissions standard from } \\
\text { lorries }\end{array}$ & $\mathrm{P}$ & 0.52 & 0.77 & 0.45 \\
\hline Passenger cars $\mathrm{HC}$ emissions & $\mathrm{P}$ & 0.85 & 0.78 & 0.48 \\
\hline Sulphur content in gas oil & $\mathrm{P}$ & 0.02 & 0.52 & 0.93 \\
\hline $\begin{array}{l}\text { Industrial discharges in surface water } \\
\text { chromium }\end{array}$ & PP & 0.87 & 0.83 & 0.22 \\
\hline $\begin{array}{l}\text { Industrial discharges in surface water } \\
\text { BOD }\end{array}$ & PP & 0.96 & 0.64 & 0.37 \\
\hline $\begin{array}{l}\text { Large combustion plants } \mathrm{SO}_{2} \\
\text { emissions }\end{array}$ & $\mathrm{pp}$ & 1.00 & 0.47 & 0.43 \\
\hline $\begin{array}{l}\text { Industrial discharges in surface water } \\
\text { zinc }\end{array}$ & pP & 0.81 & 0.81 & 0.45 \\
\hline $\begin{array}{l}\text { Industrial discharges in surface water } \\
\text { lead }\end{array}$ & $\mathrm{PP}$ & 0.87 & 0.82 & 0.52 \\
\hline Heavy fuel oil levy for industry & $\mathrm{PP}$ & 0.79 & 0.59 & 0.56 \\
\hline $\begin{array}{l}\text { Large combustion plants } \mathrm{NOx} \\
\text { emissions }\end{array}$ & PP & 1.00 & 1.00 & 0.56 \\
\hline $\begin{array}{l}\text { Industrial discharges in surface water } \\
\text { copper }\end{array}$ & PP & 0.87 & 0.78 & 0.63 \\
\hline Noise level working environment & PP & 1.00 & 1.00 & 0.72 \\
\hline $\begin{array}{l}\text { Large combustion plants dust } \\
\text { emissions }\end{array}$ & $\mathrm{PP}$ & 0.96 & 0.22 & 1.00 \\
\hline Motorway noise emissions & NPP & 1.00 & 0.77 & 0.72 \\
\hline Coliforms in bathing water & NPP & 0.60 & 0.96 & 0.73 \\
\hline Electricity tax for households & NPP & 1.00 & 1.00 & 0.78 \\
\hline Glass reuse/recycling target & NPP & 1.00 & 1.00 & 1.00 \\
\hline Paper reuse/recycling target & NPP & 1.00 & 1.00 & 1.00 \\
\hline
\end{tabular}

P: Product Standard; PP: Process Standard; NPP: Non-trade-related Policy; obligatory items in bold. 
but complementary perspectives and indicators. While with sigmaconvergence, the focus is on changes in the variation of policies, the concept of beta-convergence is applied to investigate whether changes in variation actually coincide with processes of catchingup between leader and laggard countries. The concept of gammaconvergence further complements our understanding of processes of policy convergence, as it sheds light on the different ways countries become similar, from a complete change of role from former frontrunners and latecomers on the one hand to sigmaconvergence without major turbulences in terms of country rankings on the other hand.

Table 5.9 provides a synthesis of the convergence results for the twenty-one policy setting items under investigation, listing the convergence record for each item in light of the three different approaches mentioned above. In this context, we can identify several patterns with regard to the results obtained by different convergence concepts.

First, there are cases in which we find concurrent evaluations for all convergence concepts. For instance, for NOx emissions from large combustion plants, we find high levels of sigma-, beta- and gamma-convergence for the period of the 1990s, while no convergence (regardless of the concept applied) is found for the previous decades. This suggests that during the 1990 s, the setting values for this item were not only characterised by a strong decrease in variation, but also that laggard countries were catching up with the leaders. Moreover, catching-up coincided with considerable changes in country rankings (i.e., processes of overtaking).

Second, there are constellations which are characterised by rather similar assessments for two convergence approaches. This applies, for instance, to the regulation of $\mathrm{SO}_{2}$ emissions from large combustion plants with respect to sigma- and beta-convergence. Similar evaluations in terms of beta- and gamma-convergence, by contrast, can be found for NOx emissions from passenger cars and the regulation of noise levels for the working environment. In these 


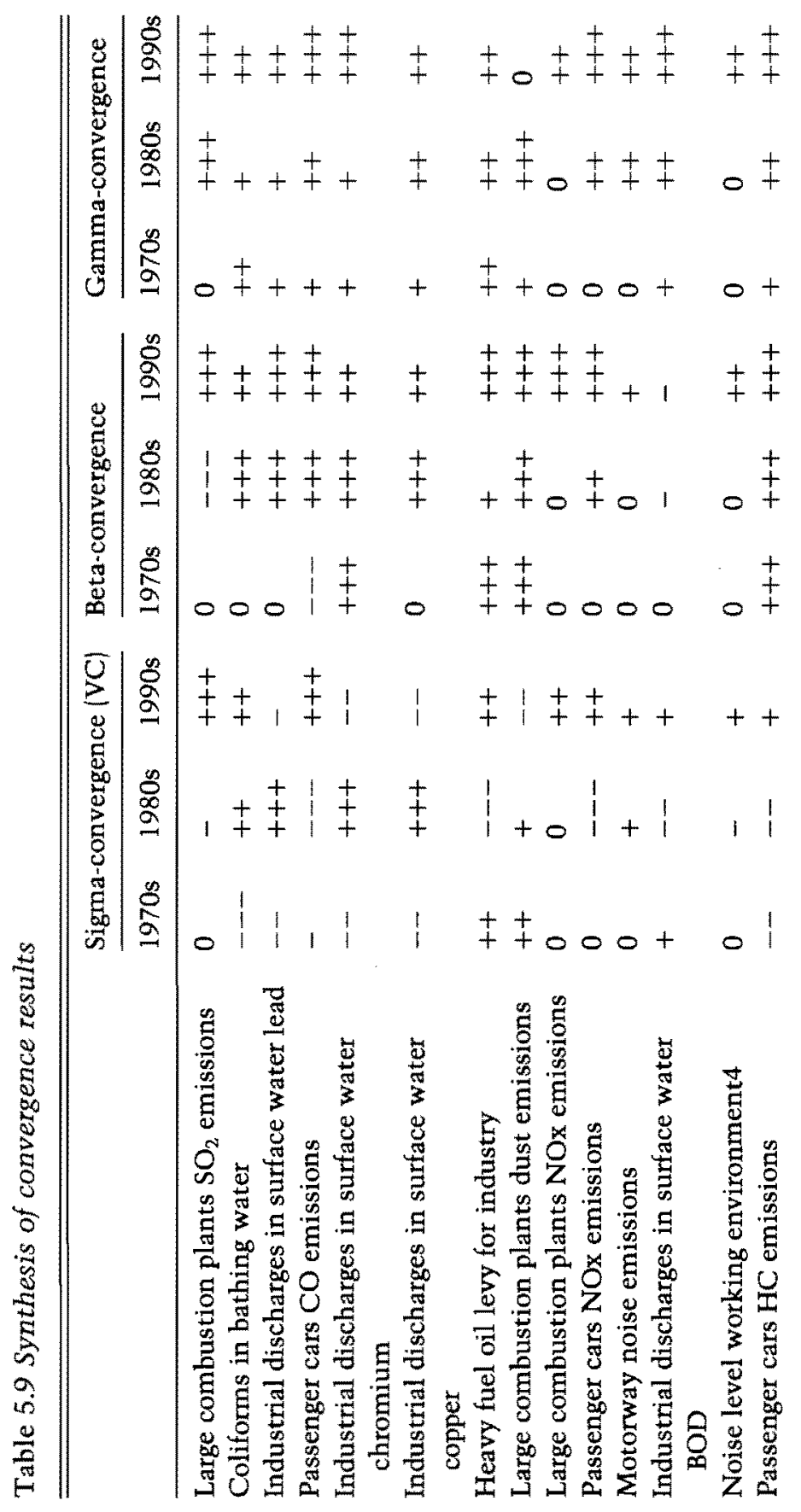




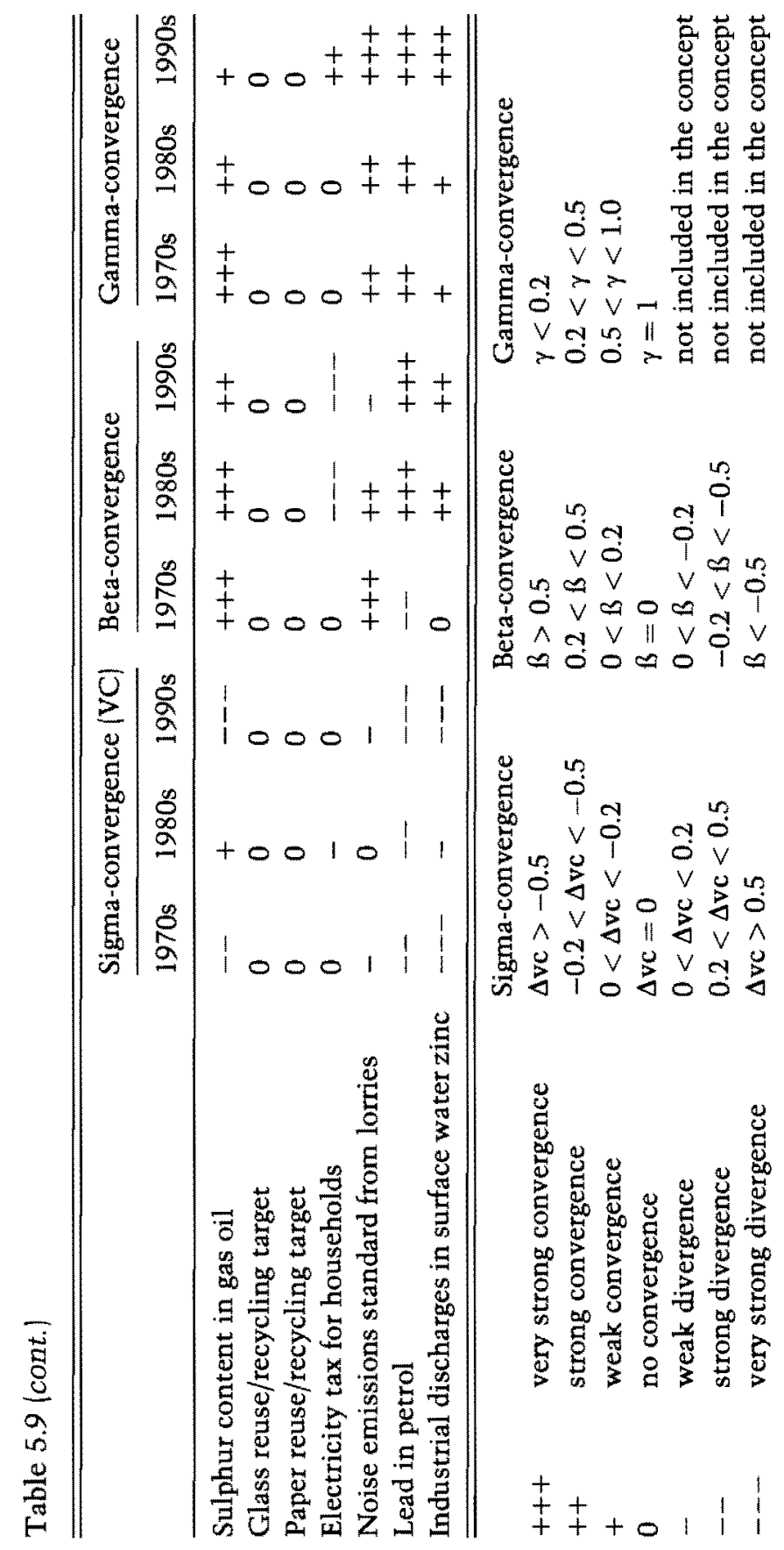


cases, processes of catching-up were accompanied by respective changes in country rankings.

Third, there are several constellations in which the different approaches arrive at rather different assessments of convergence. We find cases in which mobility changes took place without parallel processes of catching-up (e.g., dust emissions from large combustion plants, industrial discharges of BOD into the surface water). We also observe the occurrence of mobility changes that are accompanied by neither sigma- nor beta-convergence (e.g., electricity tax levels for households). Moreover, there are cases of beta- and gammaconvergence which did not result in corresponding reductions in the variation coefficient. Examples for this scenario refer to the regulation of sulphur content of gas oil, noise emissions standard from lorries, lead in petrol and industrial discharges of zinc into the surface water.

In order to illustrate the varying assessments of convergence based on these different approaches, we have selected two policy items for a more detailed analysis, namely $\mathrm{CO}$ emissions from passenger cars and industrial discharges of zinc into the surface water. In the first case, we find a rather mixed pattern of concurrent and contradictory assessments of sigma-, beta- and gamma-convergence over time, while for the latter example, as mentioned above, assessments differ for sigma-convergence on the one hand and beta- and gamma-convergence on the other hand.

Figure 5.7 shows the development of CO emission standards for passenger cars, an environmental product standard for which international harmonisation at the level of the EU existed since 1970 (the beginning of our observation period). The development for the 1970s can hardly be interpreted in view of the low number of cases (only the standards for France and the US can be displayed). ${ }^{7}$ The development is similar for other car emissions.

${ }^{7}$ From the selected ten countries, Germany had also adopted a limit value by 1970. However, for lack of comparability with the standards of the other countries, the German value is not displayed in the table. 


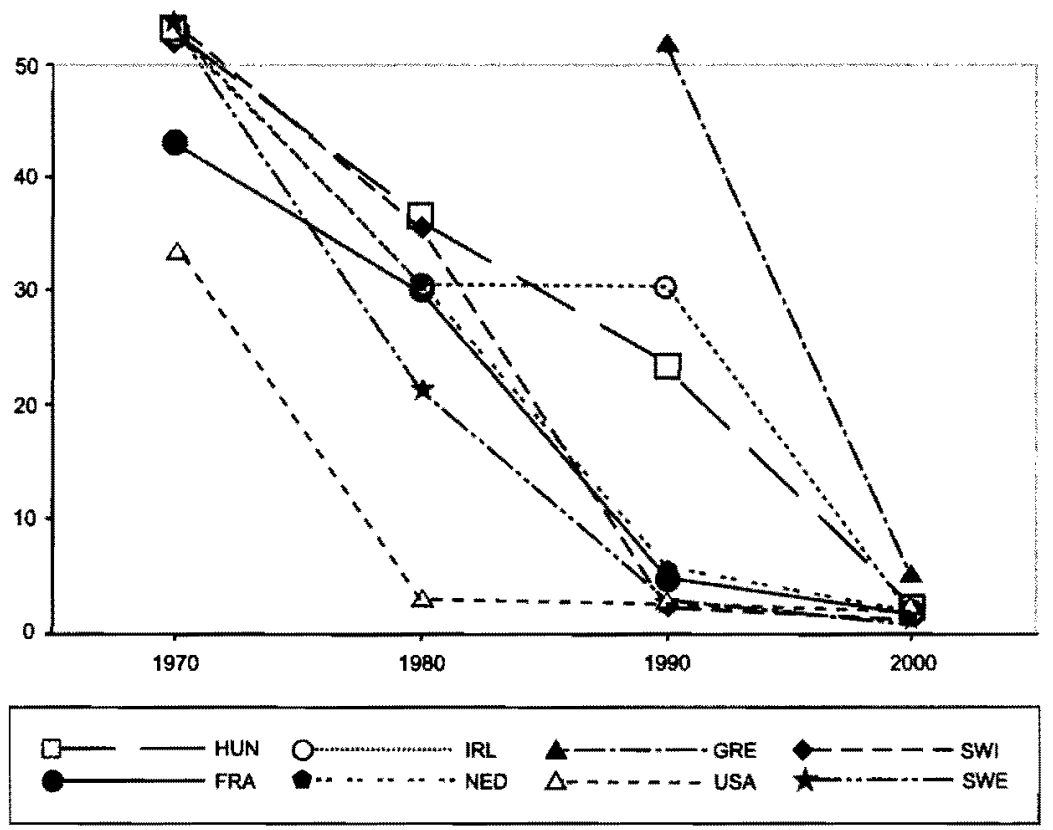

Figure $5.7 \mathrm{CO}$ emissions from passenger cars $[\mathrm{g} / \mathrm{km})$

The increase of the variation coefficient indicates sigmadivergence between 1980 and 1990 but convergence between 1990 and 2000 (compare table 5.6 above). This is caused by the fact that during this period, Scandinavian countries as well as Austria and Switzerland introduced the US standards that were stricter than EU standards at that time. As a result, we find considerable changes in country rankings and strong beta-convergence for this period. Interestingly, however, the evidence of sigma-divergence /measured by an increase in the variation coefficient) seems to be in contradiction with the optical impression of convergence - a problem we will take up again below.

By contrast, for the 1990 s, strong sigma-convergence can be observed which coincides with parallel developments of catching-up and ranking changes. The latter can be illustrated by the US which turned from a leader country and early adopter into a laggard country during the 1990, being overtaken by the stricter EU standard. An 
inverse pattern can be observed for Hungary which introduced a rather weak standard in 1980 and adopted the strict EU standard during the 1990s.

As already mentioned above, the observation of increasing variance during the 1980 s is somewhat contradictory with the optical impression - a phenomenon that can be traced to the fact that sigmadivergence is basically triggered by outlier countries. In order to take these effects into consideration, figure 5.8 analyses the variation of settings on the basis of box plots. Box plots display the distribution of values for each point in time. Each box includes 50 per cent of all values: the upper and the lower quartiles delimit the box on both sides. In contrast with convergence analysis based on the variation coefficient, outliers and extreme values are displayed separately. This way, they do not influence the length of the box. The line in the middle of each box represents the median: 50 per cent of all values are below, 50 per cent above this value. ${ }^{8}$ The length of the box represents the degree of variation: the longer the boxes, the less similar are values on this variable. Decrease in the length of a box can be interpreted as the occurrence of sigma-convergence.

Figure 5.9 displays changes in variation on the basis of both perspectives distinguished in section 5.4 .1 above. The figure on the left includes the data for all countries, implying that the number of countries might vary over time. On the right side, by contrast, only those countries are taken into account that had introduced a policy by the year 1980 . For both perspectives, the box plots indicate strong decreases in variation throughout the whole observation period, including the period of the 1980s. This finding points to certain shortcomings of convergence analysis solely based on changes in the variation coefficient, which does not take into account potential effects emerging from outlier values.

\footnotetext{
8 In some cases, the median is at the level of the upper or lower end of the box and hence not displayed separately. The additional line below or above the box describes the range for 90 per cent of all values. This line is not always displayed, as in some cases all values are within the 50 per cent range displayed by the box.
} 


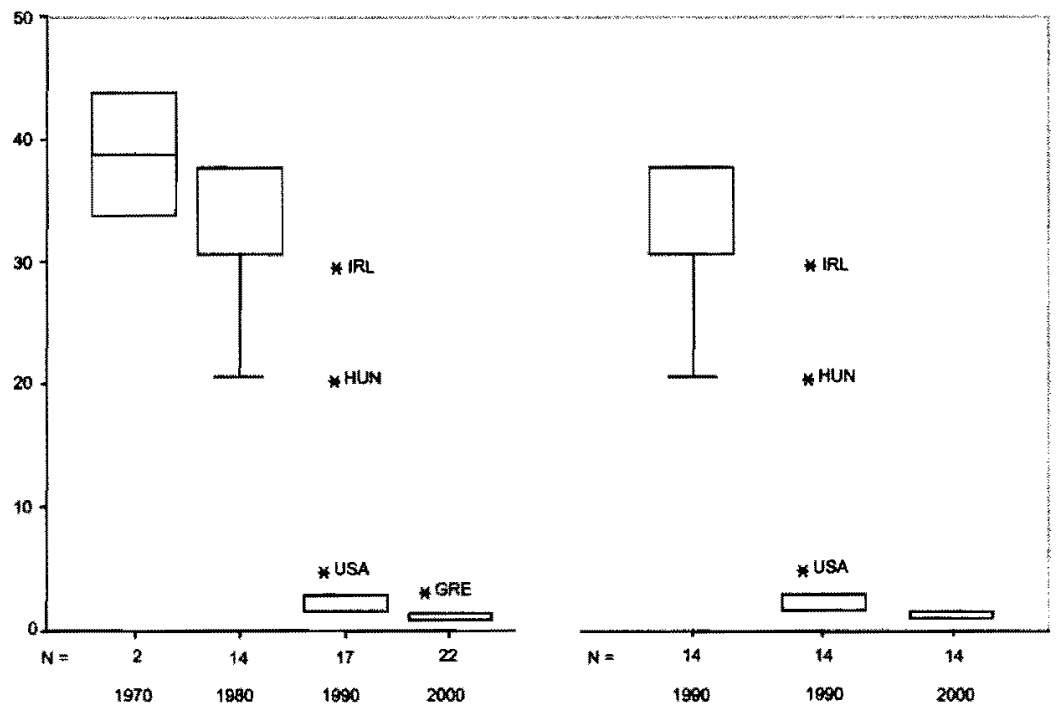

Figure $5.8 \mathrm{CO} \mathrm{cmissions} \mathrm{from} \mathrm{passenger} \mathrm{cars}[\mathrm{g} / \mathrm{km}]$ - box plots
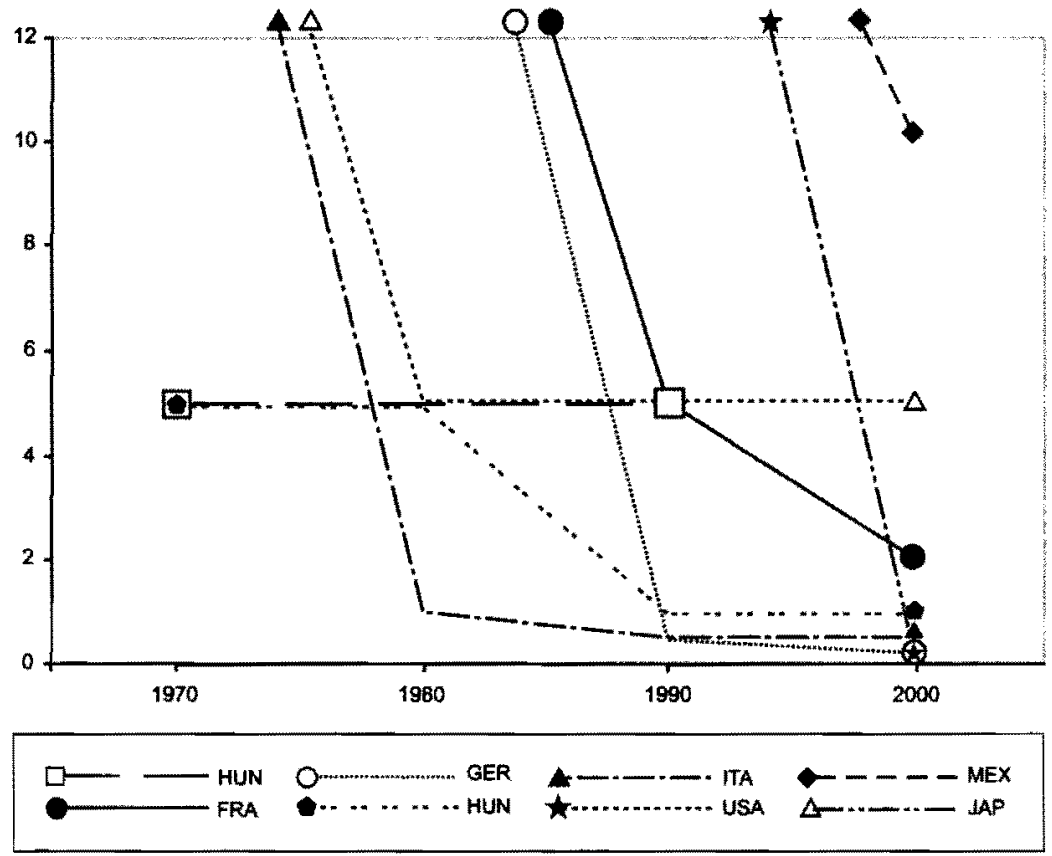

Figure 5.9 Industrial emissions of zinc into the surface water $(\mathrm{mg} / \mathrm{H}$ 
Similar patterns emerge when looking at our second example, the regulation of industrial discharges of zinc into the surface water. The zinc standards share with the regulation of car emissions that they are trade-related lalthough constituting process rather than product standards). In contrast to car emissions, however, zinc standards constitute a non-obligatory item; i.e., for this policy, no obligatory policy at the international level has been adopted during the observation period. Figure 5.9 shows the development of setting values for this item. The development is similar for the other heavy metal emissions in our sample.

The coefficient of variation throughout the whole period under study reveals a clear pattern of divergence (see table 5.6 above). Again, this result is strikingly different from the optical impression. An important reason accounting for divergence has to be seen in the number of new policy adoptions during the 1980s and 1990s. As a result, the range of values and their variance significantly changed over time. But even if only those countries are taken into account for which a value was existing already in the previous time period, no clear tendency of convergence can be observed.

During the 1980 s and the 1990 s, we find increasing variance, notwithstanding the fact that in both decades processes of catchingup and changes in country rankings have taken place. Looking at individual countries, the shift of Japan from an early leader to a laggard country is striking. This is in strong contrast with the German development. Germany introduced a limit value only in 1990 , but quickly emerged as the strictest regulator in the following years. Contrary to the Germans, Hungary was one of the first countries to introduce limit values. Moreover, the Hungarian standards have been significantly strengthened during the 1980s and the 1990s - again illustrating the rather progressive environmental policy in this country lat least with respect to legally defined level of regulation, leaving questions of practical enforcement asidel.

However, as with passenger car emissions, the finding of sigmadivergence is modified when relying on box plot analysis. Figure 5.10 


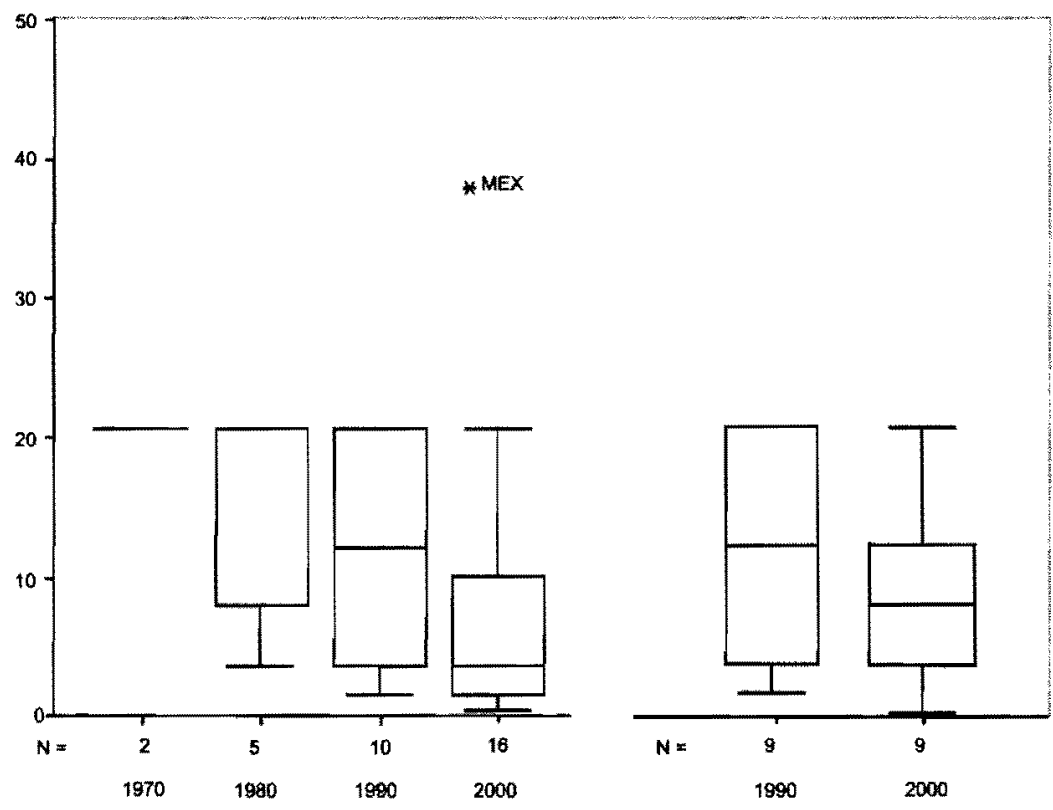

Figure 5. Io Industrial discharges of zine into the surface water $[\mathrm{mg} / 1]-$ box plots

indicates policy convergence during the 1990s for a core group of countries, whereas the outlying countries keep their position. While for the earlier periods under investigation, both box plot analysis and the variation coefficient indicate divergence, the interpretation offered by both instruments points to different directions for the period between 1990 and $2000 .{ }^{9}$ This picture of different interpretations is confirmed, regardless of the selected convergence perspective (perspective 1 on the left, perspective 2 on the right side of the figure).

In summarising our analysis of convergence on policy settings, the following aspects are of particular importance. First, when looking at the coefficient of variation, we find only modest increases in the similarity of policy settings (sigma-convergence) for the period

${ }^{9}$ One of the ten countries in 1990 , Belgium, has a missing value in 2000. 
of the 1990s. With regard to different policy types, we find convergence for non-trade-related settings, while the variation coefficient indicates even diverging tendencies for trade-related settings - a finding that seems to be in contradiction with the expectations derived from theories of regulatory competition. Similarly striking is the fact that convergence on non-obligatory setting items is slightly stronger than is the case for obligatory settings.

Second, in contrast with the assessment for sigma-convergence, there is a general picture of catching-up (beta-convergence), with laggard countries displaying higher change rates in terms of policy strengthening than the leader countries. This development coincides with considerable changes in country rankings (gamma-convergence). Both patterns are more pronounced for trade-related policies than for non-trade-related items.

Third, as regards the direction of convergence, empirical results show that there is a general tendency of a continuous strengthening of environmental standards, which is most pronounced for trade-related policies. These findings therefore provide no support for any races-to-the-bottom, as predicted by theories of regulatory competition.

Fourth, the partially different assessments of variance changes, as obtained by variation coefficients and box plot analysis, indicate potential limits of an aggregate analysis based on the former instrument, given the possibly 'disturbing' influence of outlier countries on the assessment.

\subsection{CONCLUSION}

In this chapter, we have relied on common approaches to analyse cross-national policy convergence on the basis of aggregate data. In particular, we analysed if and to what extent (1) the variance in environmental policies in the twenty-four countries under study decreased or increased over time, (2) changes in average levels of regulation took place and (3) there are developments of catchingup and ranking changes between leader and laggard countries. On 
the basis of our analysis, several general empirical patterns can be identified.

First, there is a differentiated picture with regard to the occurrence of cross-national policy convergence (in terms of variance decreases over timel. While for the policy settings and policy instruments, we can identify both decreases and increases in variation over time, there is strong convergence when it comes to the dimension of policy presence. Moreover, convergence patterns vary across different item sub-groups. Second, when analysing convergence for the different decades under investigation, the 1990s emerge as the period during which the strongest developments of sigma-convergence took place, regardless of the policy dimension and sub-group under investigation. Third, our empirical results indicate a very clear trend with regard to the direction of convergence. There is no evidence for racesto-the-bottom. On the opposite side, the development of policy settings is generally characterised by an upwards shift of regulatory requirements. Finally, there is evidence of considerable processes of catching-up and ranking changes between leader and laggard countries throughout the whole observation period, notwithstanding the fact that these developments need not necessarily coincide with sigma-convergence.

While the application of complementary concepts of and perspectives on convergence offers a highly differentiated assessment of complex empirical developments, the analysis of aggregate data, on which these concepts are based, is nevertheless characterised by several shortcomings.

On the one hand, the analysis of aggregate data might imply misleading or incomplete interpretations of our empirical data. These deficits are closely related to the concept used to determine sigma-convergence and are not fully compensated for by alternative concepts of beta- or gamma-convergence. As the variation coefficient is calculated on the basis of the whole sample of countries, similarity increases among country sub-groups might be overlooked. It is even conceivable that one or two outliers may lead to an increase in the 
variation coefficient, although the other countries are converging. This point is driven home by the fact that, in many instances, our finding of increasing variation coefficients coincided with the contradictory graphical impression of convergence. What is more, on the basis of the variation coefficient, convergence can only be assessed for metrical, but not for nominal, data. From this it follows that sigmaconvergence on policy instruments or the presence of policies cannot be analysed on the basis of this approach. To provide evidence on convergence with respect to the latter policy dimensions, we therefore had to rely on alternative forms of illustration.

On the other hand, in relying on aggregate data, we are not able to account for the performance of individual countries or groups of countries in comparison to the whole sample. The variation coefficient constitutes no reference point against which developments in one or more countries can be assessed. As a consequence, it is impossible to test theoretical explanations for country-specific patterns. In view of these deficits associated with aggregate data analysis of convergence, the following chapters offer two innovative tools for the assessment of cross-national policy convergence, which take account of these limitations. 